\title{
Wide-Area Decontamination in an Urban Environment after Radiological Dispersion: A Review and Perspectives
}

\author{
Michael D. Kaminski* \\ Telephone: 630-252-4777 \\ Fax: 630-972-4499 \\ Kaminski@anl.gov \\ Nuclear Decontamination and Separations \\ Nuclear Engineering Division \\ Argonne National Laboratory \\ Sang Don Lee and Matthew Magnuson \\ US Environmental Protection Agency \\ Office of Research and Development \\ National Homeland Security Research Center
}

Word count: 12,092 .

\begin{abstract}
Nuclear or radiological terrorism in the form of uncontrolled radioactive contamination presents a unique challenge in the field of nuclear decontamination. Potential targets require an immediate decontamination response, or mitigation plan to limit the social and economic impact. To date, experience with urban decontamination of building materials - specifically hard, porous, external surfaces - is limited to nuclear weapon fallout and nuclear reactor accidents. Methods are lacking for performing wide-area decontamination in an urban environment so that in all release scenarios the area may be re-occupied without evaluation and/or restriction. Also lacking is experience in developing mitigation strategies, that is, methods of mitigating contamination and its resultant radiation dose in key areas during the immediate aftermath of an event and after lifesaving operations. To date, the tremendous strategy development effort primarily by the European community has focused on the recovery phase, which extends years beyond the release event. In this review, we summarize the methods and data collected over the past 70 years in the field of hard, external surface decontamination of radionuclide contaminations, with emphasis on methods suitable for response to radiological dispersal devices and their potentially unique physico-chemical characteristics. This review concludes that although a tremendous amount of work has been completed primarily by the European Community (EU) and the United Kingdom (UK), the few studies existing on each technique permit only very preliminary estimates of decontamination factors for various building materials and methods and extrapolation of those values for use in environments outside the EU and UK. This data shortage prevents us from developing an effective and detailed mitigation response plan and remediation effort. Perhaps most importantly, while the data available does include valuable information on the practical aspects of performing the various remediation methods including costs, coverage rates, manpower, pitfalls, etc., it lacks the details on lessons learned, best practices, and standard procedures, for instance, that would be required to develop a mitigation strategy. While the urban decontamination problem is difficult and there is much more research to do, the existing literature provides a framework for a response plan. Using this
\end{abstract}


framework, in conjunction with computer modeling and relevant data collection, can lead to development of appropriate plans and exercises that would permit development of a mitigation and remediation response.

\section{KEYWORDS}

Decontamination; remediation; radionuclide dispersal device; nuclear fallout; radioactive contamination.

\subsection{INTRODUCTION}

Nuclear decontamination is a well-established field in the nuclear industry, practiced during routine operations [1] or in decommissioning of a nuclear facility [2]. Decontamination methods include various chemical and physical means of removing radioactivity so that the material may continue in operation, be handled with minimally incurred radiation dose, be disassembled for transport and disposal, etc.. While facility decontamination can be a very complicated undertaking, it is considered a small-scale operation compared to cleanup after a large, uncontrolled releases of radioactivity to the environment, as was the case with the Chernobyl nuclear reactor accident in 1986 and, most recently, with the reactor accident at Fukushima. The challenges experienced during the resulting remediation of (the process of cleaning-up from) these accidents highlight the limited experience and lack of effective methods for performing wide-area remediation, whether in a rural or urban environment.

But, it is not as though the scientific community has not studied extensively remediation options for these and other nuclear threats. The advent of techniques for nuclear decontamination was in response to concerns over nuclear weapon fallout during the cold war and then with the realization of our unpreparedness for a meltdown accident in a nuclear power reactor. Recently, serious concerns have grown over nuclear terrorism in the form of a kiloton or larger explosion from a crude nuclear fission device (improvised nuclear device, IND) [3] or radiological terrorism via a radionuclide dispersal device (RDD or "dirty bomb") that would scatter radionuclides of cesium, strontium, cobalt, or various actinides (among other possibilities) by low-technology means or by chemical explosives [4].

Both an IND and an RDD could be deployed in an urban area, which would lead to distinct challenges in addressing the objectives of remediation activities. For instance, response to IND and RDD incidents may involve activities designed to reduce contamination and dose levels but not necessarily be optimized for decontamination activities performed as part of the larger cleanup process, which involves characterization, waste treatment, dismantlement, demolition, and disposal work. The activities designed to reduce contamination and dose levels may be instituted to reduce exposure levels during emergency operations or to reopen critical infrastructure during the early phases of incident response "when immediate decisions for effective use of protective actions are required" and "may last from hours to days" [5]. For purposes of this paper, such activities will be referred to as radiological contaminant "mitigation," in which case reductions in contaminations and dose levels may not meet final cleanup levels. All remediation activities may involve the same techniques, but effective application of these techniques during mitigation may make later clean-up activities faster and more effective. An example of mitigation is washing down roadways to allow early responders to continue to utilize these roadways for life saving and property preservation activities. However, if not performed in an appropriate manner, such washing down may spread 
contamination into critical wastewater infrastructure, impact downstream water uses (such as drinking water utilities that utilize water sources affected by contaminated wash-down water), and other cascading impacts. These cascading impacts may make clean-up from the incident much more costly and lengthy.

From a mitigation and decontamination point of view, an IND differs little from a tactical nuclear weapon, except for the scale of the potential damage. However, if the IND is in an urban area, mitigation operations may be needed immediately after the event to lower radiation doses for emergency responders. Unlike a nuclear reactor accident or nuclear detonation, the contamination resulting from an RDD could be significantly different in its chemistry and mode of deposition presenting both challenges and opportunities to enhance mitigation and decontamination. (We intend to use "chemistry" throughout as a complicated function of the contaminant physical and chemical form, its reactivity to a surface that may evolve over time due to moisture, chemicals present from remediation activities, and/or migration into a material or through the environment.) Consider that radioactive plumes observed from a reactor accident and nuclear detonation outside the immediate blast zone will be found primarily at high altitude, "raining down" on mostly horizontal surfaces like roofs, roadways, and fields. By contrast, releases of radioactivity from an explosive RDD may occur at much lower temperature, resulting in radioactive plumes that may not rise above building tops. In other words, the deposition and fallout pattern from a potential RDD-type of detonation would be different from that of a nuclear reactor accident or an IND [6]. In congested urban centers with tall buildings, deposition of radioactivity from an RDD is expected to be across the facades of buildings, as well as on the horizontal surfaces of lower lying structures. Specifically, models show that a detonation at ground level will result in a plume that may remain close to the ground tortuously flowing in and around buildings during its passage downwind in downtown areas (Fig. 1) [7]. How these models relate to surface contamination and subsequent requirements for mitigation or remediation have not been established but different street level geometries and building material types might increase in relative importance depending on distance from the release point. Moreover, the contamination pattern and size of the area containing the highest levels of radioactivity, thus requiring mitigation for an $\mathrm{RDD}$, may be much different than that affected by an IND or reactor accident, because the movement of the plume is restricted by structures close to the ground surface. (Note that the total area requiring decontamination resulting from an $\mathrm{RDD}$, IND, or reactor accident could be equal in size, depending on the scenario.) Since the zone requiring mitigation from an RDD may be isolated to a comparatively small area, can mitigation operations be implemented immediately after the event to lower radiation doses for emergency responders and also take advantage of the chemistry of the newly deposited radionuclides so that they are easier to remove later?

Thus, the peculiarity of an RDD threat begs the question of whether it presents unique remediation challenges. The UK Recovery Handbooks for Radiation Incidents [8] provide estimates of the gamma doses following surface deposition of Cs-137 and Sr-90 from a reactor accident or nuclear detonation. However, Nisbet et al. note that the "information is not necessarily appropriate for releases occurring within an inhabited area (e.g. a dirty bomb), as the distribution of contamination between surfaces may be very different," as suggested by Figure 1. In the United States, Chen and Tenforde [9] cited Government Accounting Office reports [10, 11] noting that "current research efforts have focused mainly on predicting the effects of radiation release through simulation, small-scale testing, and theory, otherwise lacking full-scale field testing and verification." The reports also recommend research in "developing standardized 
guidance for technology deployment and for cost-effective guidance on the efficacy and effectiveness of cleanup technology. The availability and applicability of such information need to be well developed, compiled, and documented [9]." Chen and Tenforde also pointed out that "research should be continued and also further expanded in areas identified as critical to developing a basis for decisions". Medalia [12] suggested a potential gap in our understanding of RDD-related countermeasures since we have no database of information specific to RDD decontamination. Elcock et al. suggested that the very methodology for planning a decontamination effort needs to be addressed in accordance with a goal of re-occupying residential and business districts [13].

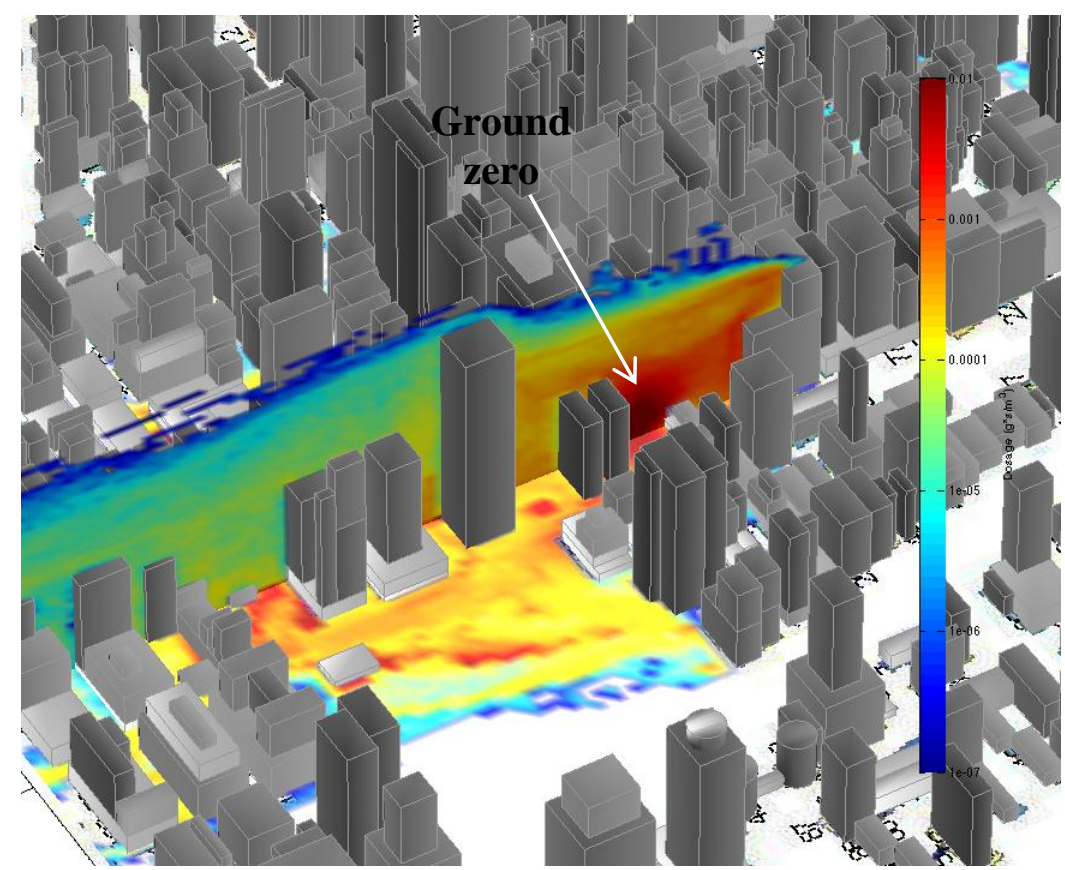

Figure 1. Simulation of the explosive release of $2300 \mathrm{Ci}$ of a Cs-137 (as CsCl) RDD made with 1.5 tons of ammonium nitrate/fuel oil in downtown Denver, Colorado [7]. Red denotes relatively high contamination levels and blue denotes relatively low contamination levels [14].

To assess gaps in the data for mitigation and remediation operations, we have reviewed the literature associated with the decontamination of urban environments, specifically, the hard, porous exterior of urban structures, roadways, and walkways. We do not discuss methods of decontaminating the internal structure of buildings or rural or uninhabited environments or soil/grass/vegetation within the urban environment, nor do we discuss hard, non-porous materials such as steels or glass since these can be decontaminated with relatively simple methods, such as wiping down with a cloth or rinsing with water. These methods are discussed elsewhere $[8,15]$. In the most general sense, we will consider contaminations in the form of loosely attached particulates (loose contamination), chemically-adsorbed surface contamination (fixed contamination), and combinations of these two forms. An example of loosely attached particulates is the dust-like fallout from a radioactive plume. Fixed contamination may result from rainwater or high humidity dissolving the radionuclides from dust causing the soluble radionuclides to chemically-adsorb to sites in building materials. 


\subsection{EVOLUTION OF NUCLEAR DECONTAMINATION TECHNIQUES FOR EXTERIOR SURFACES}

There is a storehouse of information on nuclear decontamination techniques because of their relevance to the manufacture of nuclear weapons and the nuclear power industry $[1,2,16-$ 18]. In general, these techniques focus on the decontamination of non-porous surfaces such as steels, piping, tanks, and tools. They use aggressive chemicals or equipment tailored for specific purposes and, thus, are generally not suitable for exterior use due to the hazards involved or the cost of large-scale operations. Similarly, techniques for the decontamination of concrete within nuclear facilities use aggressive chemicals (e.g., strong mineral acids), physical removal of the surface (e.g., scabbling tools), or strippable coatings (for loose contaminations). Many of these techniques are not suitable for large-area exterior use either, because of the cost of specialized equipment, the time to apply the techniques, and number of skilled workers required for effective use of the techniques. Techniques for decontamination of concrete within nuclear facilities will not be mentioned further, except for those that appear to be applicable to the wide-area, exterior, urban cleanup scenario and the RDD.

2.1 The U.S. Military and Nuclear Fallout. For some time, the U.S. military has been acutely aware of the problem of decontaminating hard, external materials following a nuclear detonation. Nevada Test Site researchers, for example, studied the characteristics of fallout, such as the radioisotope distribution patterns along the fallout path, and the characteristics of the fallout particles to develop effective decontamination methods [19]. Since the vast majority of radioactivity would be from very short-lived radioisotopes, the first step for areas in the fallout path would be to simply wait until the radioactivity associated with shortlived isotopes (radioactive half-life less than days-to-months) decays, so the focus of this study was on long-lived radioisotopes (half-life greater than months or years). It is instructional to point out that an RDD may contain one or a few radioisotopes [12], chosen by the perpetrators to not include isotopes that decay quickly. Thus, an option to "wait" for decay will likely not be viable. Two major contributors were identified in these military studies. The first was the radioactivity associated with solid particulate $(>10 \mu \mathrm{m})$ that condensed close to ground zero. For nuclear detonations, these particulates contain mixed fission products and activation products. Second, only the most volatile isotopes could be carried far along the plume, of which cesium is the most important [20]. Cesium could be found on fine particulates deposited many miles from the detonation or concentrated into falling rain or snow and was associated with particles $<10$ $\mu \mathrm{m}$.

The first reports describe techniques for eliminating the solid particles of nuclear fallout through various washing techniques [21-28]. These techniques included fire hosing with and without detergent scrubbing [21,26,27], vacuum sweeping of roadways using contemporary (1960's) street sweepers [24, 28], and various commercial-off-the-shelf (COTS) sand blasters, detergent scrubbers, washers, steam cleaners, and vacuums [23].

2.2 Nuclear Power Reactor Accidents. As the nuclear power fleet expanded in the 1970s in the U.S., the Nuclear Regulatory Commission published the first summary of decontamination methods in response to a nuclear power accident [29] by summarizing the methods cited in the previous paragraph. Then, after the first Nordic nuclear power reactor, Ris $\varnothing$ National Laboratory researchers published calculations of the impact of a core meltdown on Danish territory [30]. They followed up with a study of the potential measures that could be taken to reduce radiation levels due to fallout [31]. Their study was primarily a review of the techniques gathered by the U.S. during the 1960s, including high-pressure water 
decontamination [32] and vacuum-sweeping of paved areas [23]. This review also covers Roed's work [33], which first identified the difficulty in removing radioactive cesium deposited onto roofing material after it has rained. The United Kingdom [34] initiated laboratory studies on sandblasting, steam cleaning, and chemical decontamination methods with hydrochloric acid and ammonium nitrate wash to remove cesium from new and old building materials after both wet and dry deposition.

The reactor accident at Chernobyl in 1986 provided a wake-up call to the nuclear community on the need for a formal plan of action to institute large-scale decontamination measures. A summary publication by the International Atomic Energy Agency (IAEA) on largescale environmental decontamination methods [35] quickly followed. The IAEA recognized that the methods developed for decontamination after a Chernobyl-like accident in the areas immediately surrounding a nuclear reactor and during decommissioning of nuclear facilities would be too expensive for large-scale use. Also, methods developed for environmental cleanup concentrated on grasslands and, therefore, were more applicable to agricultural fields.

In addition, methods developed for removal of contaminated particulate were developed for weapons-related fallout with particles characteristically larger than $10 \mu \mathrm{m}$ in size, while flushing and vacuum techniques were largely ineffective on the small particles deposited far from the reactor $[28,32,37,38]$.

The fallout from the Chernobyl reactor plume provided a unique test bed for organized, international studies on actual contaminated materials. Germany, Denmark, Russia, and the United Kingdom performed original experiments with building materials contaminated from the Chernobyl accident [39-46]. Revised summaries and evaluations of the state-of-the-art for remediation of urban building materials and roadways based on this new international effort were then published in the wake of the Chernobyl accident [15, 47-53].

These studies in urban decontamination have been reviewed and organized by Brown et al. of the European Community [15] and integrated into the first comprehensive handbook published by the European Community [54] and United Kingdom [8] for a remediation response to a variety of radioactive contaminations in rural and urban environments of general applicability to Europe and the UK. These handbooks presented management options for the remediation response, including assessing the extent of contamination and developing a strategy for decontaminating various types of materials. Because they largely draw from the same underlying scientific literature, one important difference is that their approach to applying this breadth of scientific knowledge is related to conditions peculiar to the area they are intended to serve. These conditions include aspects of geography, society, legal traditions, political conditions, etc, which may vary substantially within and between countries and regions, particularly those that are large and diverse. Decision trees are provided to help with choosing decontamination methods broadly depending on the contaminated material (e.g., roofing tiles or paved areas) and estimates of the decontamination factor ( $\mathrm{DF}=$ ratio of initial contamination level to the contamination level after decontamination), cleanup cost and manpower, utility requirements (e.g., electricity, water supply), and other practical and logistical information. Importantly, the data available includes very few details on the practical aspects of performing the various decontamination methods. Such topics as lessons learned and best practices are omitted although they must have a rich knowledge of, for instance, how best to choose a particular technique in specific locations and with specific materials, operating procedures, useful instructions, reagent concentrations, information on how to collect the contaminated 
runoff, etc. Contaminations resulting in both insoluble particulate and soluble cesium are considered generally in the guidance document.

Following the Fukushima nuclear power reactor incident, the Ministry of the Environment in Japan identified and published the recommended decontamination methods and their associated processes [36]. Most of the methods listed in the guideline are composed of common procedures that can be found at construction sites or outdoor cleaning activities. The use of these low-tech methods may be due to the limited experience, availability, effectiveness, and/or utility of the nuclear specific technologies and workers for the widely impacted area. Remediation methods for large urban areas have not been further developed to date.

\subsection{SUMMARY OF METHODS AND THOROUGHNESS OF DATA IN LITERATURE}

At first glance, some aspects of the existing literature summarized above should apply to mitigation and remediation of radiological release from radiological dispersion devices (as well as nuclear weapon detonations and reactor accidents). However, to understand how the experiences with nuclear decontamination can be extrapolated to the RDD response, we should view in more detail the experimental conditions for data reported in the literature. Table 1 provides a conversion between DF and the percent removal of contamination. Table 2 summarizes the specific materials, test matrices, and primary results from all of the original works cited in European [54] and UK Handbooks [8]. Included are more recent data not mentioned in Nisbet et al. [8], such as decontamination efforts following the Fukushima catastrophe. We follow this information with a critical examination of the thoroughness of the data for each of the decontamination methods summarized in Table 2: use of clay film coating, fire hosing, high-pressure washing, ionic washing, sand blasting, street sweeping, vacuum cleaning, and other methods.

Table 1. Conversion of DF into percent removal of contamination.

\begin{tabular}{cc}
\hline & $\%$ \\
DF & Removal \\
\hline 1.11 & 10 \\
1.33 & 25 \\
2.00 & 50 \\
4.00 & 75 \\
10 & 90 \\
20 & 95 \\
100 & 99 \\
1000 & 99.9 \\
\hline
\end{tabular}

3.1 Removal of Debris, Dust, and Surfaces. What the literature teaches (see [54] and [8]) and which has been emphasized in the Japanese cleanup effort [55] is the importance of removing first the debris and loose particulate from a contaminated area since the radioactivity would have deposited onto it. Techniques such as sweeping and brushing to remove larger particulate are followed by wiping of smooth surfaces to remove the finer material. Then, more aggressive techniques can be implemented such as pressurized water cleaning that can remove a fine surface layer from concretes, tiles, and bricks. These techniques can achieve a DF often 
greater than 5. Surface removal techniques such as by grinding and ablating are often even more effective but may be limited in scale.

3.2 Strippable Coatings. Strippable coatings, polymeric solutions sprayed, dried, and peeled from surfaces, have been used extensively in the nuclear industry to control loose, dust-like, surface contamination. Tawil describes early candidates in film coatings for decontamination but the first successful coating for hard surfaces was the ALARA 1146 [56]. Demmer [57] summarizes several commercially-available films they investigated during decontamination activities at the Idaho National Laboratory including TLC Stripcoat (Bartlett Nuclear, Inc.), PENTEK 604, Sensorcoat (a formulation based on Gray [58]), and an experimental, electrochemically-assisted coating called ElectroDecon (ADA Technologies, Inc.). DF values varied but were generally 4-20 from steel and lead bricks. Andersson's study [59] investigated six film formulations for the decontamination of soils. Gray [58] describes smart coatings that incorporate bromo-pyridylazo-diethylaminophenol as a color indicator that identify the location of radioactive hotspots. He reports $\mathrm{DF}>>100$ for steels, glasses, painted aluminum, and painted cement in laboratory and during the decontamination of hot cell walls at Los Alamos National Laboratory. Parra et al. review strippable coatings and fixatives in response to an RDD [60].

3.3 Clay Film Coatings. There have been four studies on the use of clay coatings to enhance the desorption of radionuclides from porous surfaces. Since clays have a natural affinity for alkali metals, alkaline earth metals, and transition metal cations, combined with their prevalence and availability, they are a natural choice for a wide-area decontamination sorbent. Vovk et al. [44] tested a sodium form of bentonite clay (the trade name used to describe a montmorillonite clay, with silica being the primary minor component) on particulate matter near the Chernobyl reactor and soluble radionuclides further away from the reactor site. Decontamination factors were good ( $D F=2-20$ on whitewashed brick wall, 2 for smooth concrete, 3 for roofing slate, and 10 for zinc-coated iron). Ahn et al. [61] sought to improve on the work by Vovk by using a $\mathrm{NH}_{4}{ }^{+}$-loaded form of montmorillonite clay (DF $=3.45-4.55$ for slate, 1.96-2.13 for silicate brick, and 1.28-1.56 red brick). The article by Movchan et al. [62] provides no details of the composition of the "Cleadecon" clay coating that they used to decontaminate roofs and external walls of rural houses in Vladimirovka and Chernobyl, although the study appears to be relatively extensive. The method of application and removal are not given here. The study appears to use large sections of material in situ. Movchan et al. report decontamination factors for asbocement roofs ( $\mathrm{DF}=2-5.4)$ and silicate bricks ( $\mathrm{DF}=1.8-4.0)$. The use of an unnamed abrasive in conjunction with "Cleadecon" was recommended to improve decontamination, and values were given for these materials plus tiles, red brick, and rusty iron. Interestingly, they provide data on the average DF for each year of study (1987-1994), with a distinct trend toward lower DF values ( $\mathrm{DF}=15$ for 1987 and $\mathrm{DF}=1.4$ for 1994).

Roed and Andersson [40] do not describe in detail the clay paste to decontaminate in Pripyat (near Chernobyl), but "improvements" in its design by the use of a magnesium aluminosilicate palygorskite, $(\mathrm{Mg}, \mathrm{Al})_{2} \mathrm{Si}_{4} \mathrm{O}_{10}(\mathrm{OH}) \cdot 4\left(\mathrm{H}_{2} \mathrm{O}\right)$, with bentonite led to higher decontamination factors $(\mathrm{DF}=1.61)$ than earlier designs for sandstone walls. They reported treating $16 \mathrm{~m}^{2}$ of contaminated walls in Pripyat and Valdimirovka.

Interestingly, none of the above clay-assisted decontamination methods is included in the UK Handbook [8].

3.4 Fire Hosing. The studies in the 1960 s were exclusively devoted to removing 
particulate associated with nuclear detonation fallout, and they established good techniques for applying water with a fire hose to improve particulate wash-down from various paving and roofing materials $[21,22,26,27]$. The studies by Warming $[32,38]$ are the only sources we have for using a fire hose to remove the soluble radioactivity from asphalt and concrete pavement. She fire hosed a contaminated area after 4 to 179 days of natural weathering outdoors in Denmark. The data were inconclusive, and they cautioned that the few data points included all surfaces and radionuclides, preventing drawing conclusions. They reported a DF $=1.05-1.25$ for $\mathrm{Ru}-103,1.12-1.67$ for $\mathrm{Rb}-86$, and a single test with $\mathrm{Ba}-140(\mathrm{DF}=2.0)$ for asphalt, as well as $\mathrm{DF}=1.3$ and 1.1 for two test areas of concrete. The authors state that the technique was generally ineffective (average DF $=1.2$ ).

Most recently, the U.S. Environmental Protection Agency (EPA) conducted laboratory experiments on the effectiveness of fire hosing to remove aerosolized cesium chloride from concrete, brick, and asphalt. These experiments were conducted in triplicate using an experimental spray chamber that allowed measurement of spray impact pressure and angle. The EPA reported $\mathrm{DF}=3.4$ for asphalt, $\mathrm{DF}=1.85$ for brick, and $\mathrm{DF}=2.2$ for concrete [63]. These values are markedly higher than those obtained by Warming [38], but this difference likely reflects the particulate nature of the cesium in the EPA experiments, which is expected to be easier to remove from charged surfaces with pure water than the dissolved salts used by Warming.

3.5 High-Pressure Wash. There has been only one study reporting original data on high pressure washing [40]. In this study, six materials were tested in several towns contaminated after Chernobyl with DF=1.12-1.89.

3.6 Ionic Wash. The first studies on the use of dissolved cations to promote ion exchange of dissolved radionuclides was from Warming [32,38] on concrete and asphalt roadways. She reported no improvement in the use of potassium fertilizer added to the wash water but provided no data. Laboratory studies by Sandalls [34] and DeWitt [45] followed. Sandalls tested $\mathrm{NH}_{4}{ }^{+}$for removal of cesium from old and aged materials. Sandblasting (removed all cesium) and steam cleaning (DF=1) were also tested. DeWitt tested up to $1.0 \mathrm{M} \mathrm{NH}_{4}^{+}$and found that concentrations $>0.2 \mathrm{M}$ gave only marginal improvement in the DF. Interestingly, DeWitt noted that materials wetted before contamination were easier to decontaminate and surmised that this effect was due to a lack of wicking of the radioactive material since the pores were already saturated with water. Sinnuave and Olast [42] used successive methods that included a $0.1 \mathrm{M} \mathrm{NH}_{4}{ }^{+}$wash in either rinse tests or soak tests. Since the method of decontamination started with a high pressure wash $(\mathrm{DF}=2.2)$, it is not surprising that the $\mathrm{NH}_{4}{ }^{+}$ rinse did not lead to improved DF.

The study by Roed and Anderson [40] was exclusive to sandstone walls near the Chernobyl reactor site (particulate contamination) as well as farther away (soluble contamination). They found that $0.1 \mathrm{M} \mathrm{NH}_{4}{ }^{+}$removed the particulate $(\mathrm{DF}=3.03)$ better than the soluble form $(\mathrm{DF}=1.27)$. It is unclear how many data points led to these reported values.

Claret and Real et al. [64, 65] spread aerosol surrogates from a reactor meltdown explosion that contained cesium and strontium in particulate form as non-metal and transition metal oxides. Prior tests had shown that $80 \%$ of the Cs and $70 \%$ of the $\mathrm{Sr}$ could be dissolved from the aerosol particulate in rain water after $2 \mathrm{~h}$ of exposure. They demonstrated $\mathrm{NH}_{4}{ }^{+}$ solution in long washes $(2 \mathrm{~h}, 30 \mathrm{~min})$ could remove cesium and strontium activity $(\mathrm{DF}=2.5)$ from concrete if rain had not occurred prior to the $\mathrm{NH}_{4}{ }^{+}$washes. Contamination on the clay tiles proved to be more tenacious $(\mathrm{DF}=1.11)$. This study used single, large samples for each test 
condition.

Combining the ion exchange properties of excess salt and the sorption properties of the clay, an Idaho National Laboratory team developed a wash agent that is first applied and then removed either by vacuum or preferably by application of clay [66]. Few data have been released on the specific wash formulation, but it is applied to the surface first and consists of acids, chelators, and buffers that promote release of the radionuclide from the surface. The method was relatively effective in EPA tests for soluble contaminations with DF $=1.7-11$, depending on the building material and radionuclide.

With similar motivation, Argonne National Laboratory developed a hydrogel ("Argonne SuperGel") combined with excess cations to promote ion exchange of radionuclides at the surface while sorbing them into the hydrogel network [67, 68]. Strong sorbents suspended in the hydrogel can concentrate the radionuclides to reduce environmental mobility. In EPA tests, the SuperGel gave $\mathrm{DF}=1.5-3.8$, depending on the building material and radionuclide.

3.7 Sandblasting. The effect of sandblasting was reported in several studies but often as a step in successive methods. Studies on clay brick and brick walls removed most of the contamination resulting from the Chernobyl accident [40]. Sandalls [34] reported complete removal with $\mathrm{DF}>10$. Dick and Baker [23] reported that sand-blasting particulate forms of contamination was the most effective of techniques they tested.

3.8 Street Sweeping and Vacuum Cleaning. Similar to the fire-hosing studies, the efficiency of motorized street sweepers (1960's) was investigated to develop protocols for decontaminating nuclear fallout in the form of particulate. Calvert [37] describes improved street sweepers to reduce residual inhalable dust. These studies are of questionable utility, however, because the equipment is now outdated, and new environmental regulations on dust emissions have led to improved sweeper designs in the U.S. Selbig and Bannerman report more recently [69]. They did not use radioactive materials but showed, in part, the significance of particle size in the efficiency to remove particulate debris. Sinnaeve and Olast [42] were the first to investigate dry and wet deposition of cesium and found greater difficulty in removing cesium from asphalt $(\mathrm{DF}=1.11)$ than concrete (maximum $\mathrm{DF}=2.0)$ from street sweeping operations. They observed better removal of dust covered streets displaying higher dust loading than at lower dust loading. Andersson [70] mentions street sweeper tests where 50-70\% of contamination was removed. Vacuum cleaning on "two occasions" [32] was ineffective in removing simulated soluble rubidium (surrogate for cesium) from asphalt pavement.

3.9 Testing with Various Techniques. Dick and Baker [23] tested 19 surfaces with actual fallout particles from a nuclear weapon detonation using different techniques already mentioned and listed their relative effectiveness. Severa and Bár [71] provide no details but simply mention techniques that might be useful in the event of a release of nuclear material. Roed et al. [41] report on the debris removal, low pressure washing, and high pressure washing used to treat asbestos roofing in Russia contaminated by the Chernobyl accident.

Most recently, the EPA has begun evaluating technologies to mitigate specifically against an RDD [72-75] seeking to benchmark technologies available to the market if such an event occurred. These well-planned studies focus on concrete decontamination of soluble radionuclides (as a worst-case scenario of contamination), but studies on granite, marble, and limestone have been completed more recently. Various mechanical (surface removal) and chemical techniques have been tested under identical conditions. Mechanical methods worked well ( $\mathrm{DF}=1.6$ for wire brush and water jet methods, $\mathrm{DF}=2.3$ for sander, $\mathrm{DF}=14$ for diamond flap wheel, and $\mathrm{DF}=41$ for grit blaster), with the more aggressive surface scabblers producing 
higher DFs. Moreover, modern equipment allows the user to vacuum the surface particles to limit airborne contamination. Although the mechanical techniques may not be scalable to widearea decontamination because of the slow rate of coverage, they may be suitable for mitigation of smaller areas of high-value structures.

Chemical techniques may be better suited to large area (city blocks) decontamination because coverage rates can be faster depending on the technique. Those tested by EPA include Vanguard foam (an aqueous foam decontaminant, which is a derivative product of the Canadian Aqueous System for Chemical/Biological Agent Decontamination, CASCAD ${ }^{\mathrm{TM}}$ ) [74], the RadRelease ${ }^{\circledR}$ formulation, and the superabsorbing hydrogel described briefly above in the Ionic Wash section.

Following the reactor meltdown accident in Fukushima, Japan, an aggressive decontamination effort was launched by the government of Japan to assess and demonstrate technologies required for conducting effective decontamination before the full scale decontamination [76]. The demonstration was conducted covering 11 municipalities in the restricted zone or planned evacuation zone $(<20 \mathrm{~km}$ from the reactor site). Example surface decontamination methods include removal, stripping, grinding, high-pressure washing for roads and buildings $[55,77,78]$. Based on the findings from this model project, decontamination technologies have been identified and modified to meet the needs of decontamination. The full scale decontamination effort is in progress, having completed decontamination in numerous communities (Tamura, Kawauchi, Okuma, and Naraha)[77]. Unlike previous nuclear incidents, Fukushima and other areas in Japan experienced vast devastation due to a combination of earthquake, tsunami, and reactor explosion. This series of disasters demanded significant response from the government of Japan and created enormous amounts of disaster debris over huge parcels of land. Thus, the primary clean-up method has been removal of the debris and these methods are greatly utilized during decontamination of the radioactively contaminated sites. The Japanese government having collected thousands of data points thus far, the preliminary information on the decontamination strategy is instructive. Very briefly, any radioactive materials that can possibly be removed by methods other than cleaning with water are removed in advance, and other measures are taken to limit the contaminated drainage resulting from cleaning or other flows, as much as possible. The workers first remove the sediments that can be easily removed by hand and wipe the residual dirt with thick paper towels. If there is no observable decontamination effect, the objects are sprayed with water. When water is used to decontaminate houses and buildings, the workers start from high places and continue toward the ground, being careful to prevent radioactive runoff to gardens and other undesirable locations. In cases where no decontamination effect is observed as a result of pressure washing, decontamination of rooftops can be done by scraping, shot-blasting, or scrubbing with a brush. Best practices and lessons learned from the specific techniques are not included. What is evident from the data presented is the wide range of decontamination factors for a particular technique on broad classes of materials (e.g., roofs, concrete, paving). It is difficult to conclude the reason for the tremendous variance but one would expect that the DF is a strong function of the specific material type, time, and variability in the implementation of the techniques, particularly for such a large-scale and long-lasting effort. For instance, even among equally-skilled workers, it is conceivable that even small variability in implementation may significantly impact the DF, especially for techniques that are designed to be applied very rapidly and therefore may require optimal control. With still extensive data analyses to complete and a monumental effort still required, it will be some time before the data are completely analyzed, and the lessons learned 
are disseminated. The recommended methods and associated processes can be found from the Decontamination Guidelines published by Ministry of the Environment [36].

\subsection{QUALITY AND COMPLETENESS OF PRIOR DATA}

If we consider the combined data gathered thus far, we are left to conclude that the few studies on each technique permit only very cursory conclusions on decontamination factors for various building materials and methods, regardless if the contaminations arise from nuclear weapon detonations, power plant accidents, or RDDs, and regardless of whether they be mitigation activities or longer term decontamination activities for unrestricted occupation of the area. The task at hand is daunting, no doubt. With the millions of different types of building materials and complex chemistry of radionuclides in their different forms, it would be impossible to reliably cover every radioactive dispersion scenario. Plus, the criteria for clean-up have not been established (how clean is clean?). Moreover, even given the Fukushima experience, the current database of DFs should be applied cautiously in planning decontamination efforts except, possibly, for very specific contaminations such as particulate because much of the data comes from uncontrolled experiments using different materials for which there is no method of comparison. Let us examine this conclusion further.

4.1 Lack of comparable data from controlled experiments. For radioactivity rendered soluble, we learned in the previous section that material composition is an important variable in determining the effectiveness of a decontamination technique; that the DF differs between asphalt, concrete, tile, etc. (and likely different between various types of asphalt, concrete, tile, etc.); and that insoluble particulate can be removed as well as some surface particles, with smaller particles $(<10 \mu \mathrm{m})$ being more troublesome. Even though fire hosing was tested on concrete and asphalt surfaces and pressure washing was completed on different roof types, the composition of those surfaces might vary greatly between geographic regions. For instance, certain regions of the U.S. have peculiar additives for asphalt to improve durability in a harsh climate. How do these additives affect radionuclide sorption? Thousands of data points are available from Fukushima, but for any given remediation method (Table 2), there is a large standard deviation. This might be attributed to, in part, the data including many general classes of materials and also methods performed by individuals of differing proficiency relative to the skill level inherently associated with the technique. Importantly, much of the field data from Table 2 were collected on aged contamination (e.g., 3.5-years since the accident at Fukushima), whereas the DFs may be improved [62] in mitigation operations where the contamination is fresh and less weathered. Certainly, [79] the experimental studies first reviewed by Sawhney [80], further developed by Cremers et al. [81] and Comans et al. [82], and field studies by Andersson et al. [79] show that sorption behavior is an important function of time on clay minerals and building materials. Additional studies are needed to understand the effect of aging.

4.2 Limited data on location-specific material composition and orientation. Before Fukushima, there were a few studies on a few materials of many varieties. The emphasis in prior reports was on horizontal surfaces that are more important to IND or nuclear reactor releases that "rain down" from the sky, whereas for RDD, vertical surfaces may be as or more important, although the relative importance is unclear. These previous studies included field tests in Denmark, Russia, United Kingdom, Germany, and the U.S. plus several laboratory studies. All these investigations used building materials and compositions peculiar to specific locations in their respective countries. There are potentially thousands of different compositions of concrete throughout a region, particularly large ones, because concrete is often made from 
locally-available materials, which can have constituents with varying potential for radionuclide fixation. Can we draw accurate conclusions on the DF for all these types based on previous data or can materials be classified into groups to permit extrapolation from known data, such as the convincing evidence summarized by Sinnuave and Olast [42] suggests (see Ch. 6 therein)? Or are new data and/or methods required? Even though Japan has invaluably increased the number of data points by orders of magnitude for a variety of methods applicable to large-scale decontamination of buildings and other external surfaces, the Japan data are specific to the building materials of the Fukushima region. Moreover, consider the stark differences in buildings between regions and cities. For example, those familiar with the Western and Southwestern United States know that stucco external walls and clay roofing tiles are prevalent. In the Midwest, both materials are rarely used. Instead, external walls are often vinyl/aluminum siding or brick, and roofing is composition shingle. Even this regional variance hides the extremes that exist between a downtown city with tall buildings (e.g., steel, glass, and architectural concrete) and the outer city limits. As such, data are lacking for many common building materials in the U.S., including stucco, painted wood siding, and vinyl siding. The same is true for building materials around the world.

4.3 Need to consider the influence of chemical and physical form of RDD contaminants. Besides the dearth of decontamination data on various materials, data are lacking on the influence of the chemical and physical forms of RDD-derived contaminations. These chemical and physical forms might include ballistic-type particles and precipitates that rain from the sky, which may be in the form of refractory radioactive sources such as cobalt metal and strontium titanates. The form of contamination may also be a highly soluble chemical, such as salts and oxides of cesium that are extremely hygroscopic. This condition would increase its reactivity with surfaces to form cationic complexes on the substrate and reduce the effectiveness of washing techniques.

Ballistic-type contaminations might be amenable to removal using methods designed for weapon fallout particles nearer to ground zero where fire hosing, street cleaners, and highpressure wash are effective. Other contaminated particulate can be removed using techniques suitable to that size range of particle. For soluble chemical forms, the scientific community has studied the sorption of high-priority radionuclides onto some building materials. However, given the vast number of building materials found in urban areas, there are many unknowns. One might expect simple washing with potable water to be ineffective because of chemical sorption, but it may be effective in removing the pre-existing particulate debris on the surface, as the fire hose and wash method data appear to support. Thus, the ionic washes and surface removal techniques would be most germane.

4.4. Lack of details on lessons learned, best practices, and standard operating procedures. In a large-scale remediation effort, training of a sufficient number of skilled personnel will be difficult. Practical aspects in performing a remediation technique properly are critically important. Clearly the efforts from the European Community, UK, and Japan have produced many lessons learned, thoughts on best practices and written standard operating procedures. We have reference to such a document from Japan ("Good Practice Collection," see [77]). However, these have not been published in the open literature. An effort to develop remediation guidelines would invaluably benefit from such information.

4.5 Lack of details about waste generated and its management. Waste management is an enormous challenge for wide-area radiological contamination incidents, as evidenced in Japan, previous nuclear power plant accidents [83], and accidental releases of 
sealed sources [84]. Waste management needs can be different during remediation and mitigation. For RDD incidents over a wide area, literally thousands of tons of solid waste and billions of liters of contaminated water may be generated [85]. Each of the methods in Table 2 will generate some type of waste, but the specific amount and type will depend on the DFs, the material being treated, and other scenario-specific considerations. Nisbet et al. $[8,86]$ estimate waste generation and their contamination levels for all techniques and note that waste generation must be considered when selecting and applying remediation methods However, details about the resulting waste are unpredictable, although some methods seem to be inherently or by design more compatible with waste management and minimization considerations. Presumably, the waste management approaches suggested in these handbooks is compatible with the regulatory framework in the areas they are intended to serve. However, applicable regulations can vary substantially within and between countries and regions, particularly those that are large, diverse, or have not yet experienced specific types of incidents. Waste management in the long-term recovery phase of an accident has been difficult enough. How do we manage waste in a mitigation response?

4.6 Lack of details about unintended consequences. Unintended consequences of the methods in Table 2 include worker exposure, damage to material being treated, and spread of the contaminant to the environment or through the sewer/storm-water system of an urban area. Infiltration into the sewer/storm-water system has the potential to shut down the public sewer system, which could have cascading consequences to the community and its public health. While Nisbet et al. [8, 86] provide valuable information on worker protection, environmental impact, social and psychological impact and many other areas, unintended consequences vary with radioactive dispersion scenario, contaminant, and area impacted. Given the range of potential release scenarios, sufficient detail seems required to carefully consider unintended consequences when applying a mitigation technology.

\subsection{CONCLUSIONS ABOUT DIFFERENT METHODS FROM PREVIOUS DATA}

Given the very limited database as a function of specific types of materials (ASTM concrete, asphalt from a town in Denmark, etc.), and type of radioelement and its solution chemistry (cesium salt, strontium titanate, etc.), how well can we extrapolate the data collected to date for developing an effective decontamination strategy and estimating the effectiveness of these decontamination options for urban areas? Clearly, when a decontamination strategy is developed, it should include data on the specific building materials for that city or section of that city or even particular buildings or paved areas. For a mitigation strategy, a very specific location (e.g., area surrounding hospitals and ingress/egress routes) might be a priority. Once the locations are identified, the techniques summarized in Table 2 may be useful, although with many of these technologies applying them to urban areas may present logistical and technical scale-up challenges.

5.1 Strippable coatings. This method was designed specifically for loose contaminations in a nuclear facility and has been extensively used in the decontamination of nonporous materials such as metals, tools, and painted surfaces including metal surfaces contaminated after Chernobyl [87] so there is plenty of DF data and data on operational factors and cost. Brown [88] reports values used in the CONDO model for plutonium removal based on work performed at the Atomic Weapons Research Establishment. One review specifically considers their use in an RDD response [60]. However, there are limited data on the removal of fixed contaminations on porous, hard, external surfaces aside from the studies by the EPA [74, 
89]. Strippable coatings could be valuable method to control loose surface contaminations and fixed contaminations during mitigation activities although Parra et al. point out that the "...majority of studies lack quantitative data that can be used to evaluate or compare effectiveness..." and "...lack of standard testing makes comparison difficult."

5.2 Clay Film. The clay-film technique was not designed for insoluble particulate contaminations, and its applicability depends on how well one can remove similarly sized clay residue from the surface. There are too few data to reach a firm conclusion on its efficacy for soluble materials. It is worth pursuing due to the availability of clay sequestering agents to control runoff contaminations and the low cost of clays.

5.3 Fire hosing. Fire-hosing methods have focused on large particulates typical of close-range nuclear fallout. Techniques should be applicable to RDD that produce ballistic-type contaminations and condensed insoluble materials. The limited data available on soluble contaminations address only $\mathrm{Sr}, \mathrm{Cs}$, and lanthanides and are shown to be ineffective, likely due to the surface chemisorption of the radionuclides and lack of counter-ions in the water to effect ion-exchange reactions with the radionuclides.

5.4 High-Pressure Wash. The data are too few and highly variable to reach a conclusion about high-pressure washing. This technique is likely an improvement over fire hosing, since some substrate can be lifted from the surface to remove ballistic-type and condensed insoluble RDD or soluble forms sorbed onto the surface particulate.

5.5 Ionic Wash. Ionic washing can be used for soluble forms of radioactive contamination, but there are too few data to conclude whether the marginal improvements to the $\mathrm{DF}$ are due to so few data points. Since it is known that ammonium greatly improves the ion exchange of cesium from building surfaces, then why are the DFs not higher? And what is the exact mechanism for ultimate removal from the surface given the sorption sites, the microporosity, re-adsorption, and localized precipitation? Additionally, the ions promote cesium desorption from the surface and thus enhance its mobility. Once mobile, how does one capture the cesium to limit downstream contamination in the presence of competing salt? While it is well known that the DFs are influenced by selective adsorption of cesium to certain components of building surfaces (see [90]), the resulting question is how to apply the scientific knowledge to the practical reality that construction materials vary significant within and between countries and regions, particularly ones that the large, diverse, and have been constructed over a long period of time during which construction practices and material available may have substantially varied. Further research is underway to identify timely and selective application of the ion exchange method as a mitigation technology. For example, Argonne National Laboratory [91] has been developing an engineered system to integrate the mild chemical decontamination methods first discussed by Sandalls [92] and further developed by Samuleev et al. [93] with methods of water containment and radionuclide separations [91]. This wash system consists of chemical additives added in-line to fire hydrant water and natural, common solid sorbents added as the water is collected and treated for recycling in situ. The wash system is intended to be a rapidly deployable, cost-effective means for decontamination of an urban setting or mitigation to restore critical infrastructure and operational activities after a radiological release. Few test data have been reported in the open literature, but the technique is still in development.

5.6 Sand Blasting. No stand-alone studies permit a conclusion about the efficacy of sand blasting, but it operates on the mechanism of dislodging surface substrate particles, and therefore, its effectiveness on soluble contaminations will follow with the operator's ability to scour the surfaces. 
5.7 Street Cleaning. Data showed that street cleaners could efficiently remove large surface particles and high particle loading (particles per square area), but past data may be of little relevance due to antiquated machinery represented in those studies. Modern street sweepers have evolved to increase efficiency and to meet more-stringent air emission standards. Therefore, it is expected that modern street sweepers would perform better than past studies have shown. Two questions should be investigated. Could the modern street sweepers now be able to pick up fine particulate $(<10 \mu \mathrm{m})$, unlike their predecessors, and so be useful for RDD contaminations that involve smaller particulate than the large particles found near atomic bomb blasts? Since many now have water tanks to help with emissions, could an ionic wash improve DFs for soluble contaminations?

5.8 Debris Removal. From Fukushima, we are taught that the first cleanup method to implement is physical removal of debris without the use of water. This removes the particulate and condensed soluble radionuclides first and eliminates the possibility of producing soluble radioactive species that will be more difficult to remove due to chemical bonding to charged surfaces or penetration into pores within the building materials. However, the extent of debris removal may be unique to the Fukushima disaster, as it involved three virtually simultaneous disasters (i.e., earthquake, tsunami, and nuclear reactor melt-down), leading to incredible amounts of damage debris.

5.9 EPA Tested Methods. Unlike previous work, the experiments described by Drake and Lemieux [72-75] address soluble contaminations spread specifically by an RDD. These studies begin to constitute a toolbox of techniques for specific materials based on tests primarily with concrete but also some tests on granite. Limited tests included $\mathrm{Cs}$, Sr, Am, and Co contaminations. In addition, information on other factors such as cost, cleaning rate, waste volume, etc., are reported. All these techniques are still without field data, and most of the techniques tested in laboratory studies are not appropriate for wide-area applications (e.g., surface scabbling with hand-held devices). Instead, they are designed more for high-value structures that can justify more expensive techniques. The exceptions might include application of the RadRelease ${ }^{\circledR}$ formulation and the Argonne SuperGel, where the solution and gel, respectively, can be applied to larger areas, but they are still limited by the ability to vacuum the areas clean. Moreover, they require proprietary reagents and applications that may not be conducive to do-it-yourself or ad-hoc mitigation operations.

\subsection{FUTURE WORK}

Clearly, the task at hand is daunting, yet the scientific community has learned much from previous investigations and nuclear catastrophes. The lessons learned in performing the various decontamination methods must be gathered so that decisions guiding the mitigation effort can be best informed and the specific decontamination procedures can be completed most effectively. Importantly, the cleanup experiences at Fukushima are now being disclosed. The sheer size of data on decontamination factors and logistical matters will be extremely important in developing a guidance document or model, but in extrapolating the Fukushima data on DFs, the scientific community should take into account the material compositions in other regions in the U.S. and around the world.

Future needs are evident from the literature and may be informed by questions about what activities to meet these needs provide the most benefit for the given effort and cost: What is(are) the end goal(s)? Is it to reduce the dose to the first responder, reduce the dose for later cleanup activities, or to remove contamination so the area can be reoccupied without restriction? 
Is it to ensure the highest DF, since older contaminations are generally more difficult to remove due to chemical reactions on the surface?

With the goal(s) in mind, the structures and materials within the contaminated area can be prioritized for activities to meet these goals. To further refine this prioritization, urban plume models that can predict plume transport and radionuclide deposition patterns might be used to help develop spatial maps of horizontal and vertical surfaces of high-priority targets to rank material priority for testing. In conjunction, it may be useful to model the dose factor for specific cities or high-priority targets for remediation methods used to virtually clean a contaminated zone and perform a sensitivity analysis to identify what types of remediation activities have the most effect on the goal outcome (e.g., re-opening activities in a business district). For example, Thiessen et al. [94] explain that "the reduction in dose is situation specific and dependent on the characteristics of the deposition." Accurate modeling will be critical. Modelling approaches exist (see [94] for a review) but most of these are specific to nuclear reactor accident contamination and should be adapted and the databases expanded greatly to reliably predict contamination and facilitate planning efforts.

New frameworks and models could help city planners map their specific high-priority targets and plan practice scenarios. This includes a method of prioritizing efforts to areas that are of high value, have large population density, have emotional or patriotic significance, or provide higher DFs than if the cleanup was delayed and the contamination allowed to age.

Then, the scientific community can test the mitigation or decontamination method of specific, high-priority building materials under benchmark conditions and finally expand to field tests to understand logistical and field variability. These tests should include more radionuclides. Cesium is considered a major concern, but radioactive strontium, cobalt, americium, and other radionuclides might be important. The test matrix should also account for variables within materials (i.e., different formulations of concrete, tile, brick, asphalt, siding, roofing, etc.). In addition to testing existing methods, breakthroughs in large-area decontamination and mitigation methods are needed. The scientific community should develop improved methods that focus on wide-area decontamination and field test these methods. Finally, the ability to apply any method is only as good as the ability to obtain supplies and equipment to implement it, so supply chain analyses may help ensure timely response in an emergency.

Thinking more specifically about mitigation, where the response is much more immediate to the event ("early phase") and not part of the late phase recovery period, the scientific community knows much less. There is the same lack of data on radionuclide chemistry with the associated building materials. In addition, the logistics of technology application during the early phase has not been extensively studied or refined. Major questions include how can techniques be deployed in the early phase given the immediate goals of life saving and preservation of evidence, as well as the panic and the "fog of war" that is characteristic of a disaster? Can the response occur quickly enough to make a difference in radiation dose to the response workers? How can mitigation methods be integrated into an early response plan knowing the logistical and time constraints, and who will do the decontamination work? Because only limited personnel are permitted to operate in a disaster zone, will the mitigation response need to be deployed by first responders such as firefighters? Should equipment and supplies be stockpiled, and personnel actively trained/exercised to preserve the ability to respond with a mitigation effort in the early phase? These questions should be answered in addition to the other questions outlined above. 
While mitigation and decontamination of a radioactive dispersion are difficult and there is much research to do, there is some room for optimism. Very importantly, the scientific community has a framework for a response plan, in resources such as Brown et al. [15] and Nisbet et al. [8], among others, that can be used as a template for developing improved mitigation and decontamination plans. Many aspects of the decision-making process are included. The information from Fukushima will be invaluable with many additional data points and practical information on deployment, man-hours, and cost. Response plan templates, computer modeling and relevant data could be used to inform preparedness plans and support exercises in accordance with the National Planning Scenarios [95].

\section{* CORRESPONDING AUTHOR INFORMATION}

Tel.: 1-630-252-4777; Fax: 1-630-974-4499; E-mail: Kaminski@anl.gov

\section{NOTES}

The author (MDK) declares that he is one of several inventors of the Argonne SuperGel that is included in the review of decontamination methods. The authors declares no other competing financial interest.

\section{ACKNOWLEDGMENTS}

The authors thank J. Harmon and J. T. Bursey for editing the document. This work was supported by the United States Department of Homeland Security/Science and Technology Directorate in collaboration with the U.S. Environmental Protection Agency/ National Homeland Security Research Center through an interagency agreement. It has been subject to an administrative review but does not necessarily reflect the views of either Agency. The submitted manuscript has been created by UChicago Argonne, LLC, Operator of Argonne National Laboratory ("Argonne"). Argonne, a U.S. Department of Energy Office of Science laboratory, is operated under Contract No. DE-AC02-06CH11357. The U.S. Government retains for itself, and others acting on its behalf, a paid-up nonexclusive, irrevocable worldwide license in said article to reproduce, prepare derivative works, distribute copies to the public, and perform publicly and display publicly, by or on behalf of the Government.

\section{REFERENCES}

[1] K. Heinz-Neeb, Decontamination in Nuclear Power Plants, in: The Radiochemistry of Nuclear Power Plants with Light Water Reactors, Walter de Gruyter, New York, 1997.

[2] Decontamination Techniques Used in Decommissioning Activities, NEA Task Group on Decontamination, Nuclear Energy Agency-OECD, (2008).

[3] C.D. Ferguson, W.C. Potter, Improvised Nuclear Devices and Nuclear Terrorism, Weapons of Mass Destruction Commission, Stockholm, Sweden, 2004.

[4] H. Kelly, Dirty bombs: response to a threat, Journal of the Federation of American Scientists, 55 (2002).

[5] PAG Manual - Protective Action Guides and Planning Guidance for Radiological Incidents, in, U.S. Environmental Protection Agency, 2013. 
[6] S.V. Musolino, F.T. Harper, B. Buddemeier, M. Brown, R. Schlueck, Updated emergency response guidance for the first $48 \mathrm{~h}$ after the outdoor detonation of an explosive radiological dispersal device, Health Physics, 105 (2013) 65-73.

[7] WARRP Waste Management Workshop, U.S. Environmental Protection Agency, Office of Homeland Security, Denver, Colorado, (2012).

[8] A. Nisbet, J. Brown, A.L. Jones, H. Rochford, D.J. Hammond, T. Cabianca, UK Recovery Handbooks for Radiation Incidents, HPA-RPD-064, Health Protection Agency, (2009).

[9] S.Y. Chen, T.S. Tenforde, Optimization approaches to decision making on long-term cleanup and site restoration following a nuclear or radiological terrorism Incident, Homeland Security Affairs, 6 (2010) 17.

[10] B.G. Thompson, Y.D. Clarke, M.T. McCaul, Actions Needed to Better Prepare to Recover from Possible Attacks Using Radiological or Nuclear Materials, GAO-10-204, Combating Nuclear Terrorism, U.S. Goverment Accounting Office, (2010).

[11] G. Aloise, Preliminary Observations on Preparedness to Recover from Possible Attacks Using Radiological or Nuclear Materials, GAO-09-996T, Combating Nuclear Terrorism, US Government Accountability Office, (2009).

[12] J. Medalia, "Dirty Bombs": Technical Background, Attack Prevention and Response, Issues for Congress, Congressional Research Service, (2011).

[13] D. Elcock, G.A. Klemic, A.L. Taboas, Establishing remediation levels in response to a radiological dispersal event (or "dirty bomb”), Environmental Science \& Technology, 38 (2004) 2505-2512.

[14] B.A. Boughton, J.M. DeLaurentis, An Integral Model of Plume Rise from High Explosive Detonations, SAND-86-2553C, Sandia National Laboratory, (1986).

[15] J. Brown, K. Mortimer, K.G. Andersson, Countermeasures for the Management of Inhabited Areas Contaminated After a Radiological Incident, EURANOS(CAT1)-TN(05)-04, Health Protection Agency, Chilton, Oxfordshire, (2005).

[16] K.S. Dickerson, M.J. Wilson-Nichols, M.I. Morris, Contaminated Concrete: Occurrence and Emerging Technologies for DOE Decontamination, DOE/ORO/2034, Oak Ridge National Laboratory, (1995).

[17] L. Chen, D.B. Chamberlain, C. Conner, G.F. Vandegrift, A Survey of Decontamination Processes Applicable to DOE Nuclear Facilities, ANL-97/19, Argonne National Laboratory, (1997).

[18] E. Feltcorn, Technology Reference Guide for Radiologically Contaminated Surfaces, EPA402-R-06-003, U.S. Environmental Protection Agency, Washington, DC, (2006).

[19] Distribution, Characteristics, and Biotic Availability of Fallout, Operation Plumbbob, WT1488, Civil Effects Test Group, Nevada Test Site, (1966).

[20] J.R. Simmonds, S.M. Haywood, G.S. Linsley, Accidental Release of Radionuclides: A Preliminary Study of the Consequences of Land Contamination, NRPD-R133, National Radiological Protection Board, United Kingdom, (1982).

[21] C.F. Miller, The Radiological Assessment and Recovery of Contaminated Areas, Civil Effects Exercise, CEX-57.1, U.S. Naval Radiological Defense Laboratory, San Francisco, CA, (1960).

[22] W.L. Owen, J.D. Sartor, W.H. Van Horn, Performance Characteristics of Wet Decontamination Procedures, Stoneman II Test of Reclamation Performance, USNRDL-TR335, U.S. Naval Radiological Defense Laboratory, San Francisco, CA, 2 (1960). 
[23] J.L. Dick, T.P. Baker, Monitoring and Decontamination Techniques for Plutonium Fallout on Large-Area Surfaces, Operation Plumbbob, WT-1512, Air Force Special Weapons Center, Albuquerque, NM, (1961).

[24] D.E. Clark Jr., W.C. Cobbin, Removal of Simulated Fallout from Pavements by Conventional Street Flushers, USNRDL-TR-797, US Naval Radiological Defense Laboratory, San Francisco, CA, (1964).

[25] R.H. Heiskell, W.S. Kehrer, N.J. Vella, Fallout Removal Studies on Typical Roofing Surfaces for Three Size Ranges of Particles, Design Criteria for Roof Washdown, USNRDL-TR789, U.S. Naval Radiological Defense Laboratory, San Francisco, CA, (1964).

[26] L.L. Wiltshire, W.L. Owen, Removal of Simulated Fallout from Asphalt Streets by Firehosing Techniques, USNRDL-TR-1049, U.S. Naval Radiological Defense Laboratory, San Francisco, CA, (1965).

[27] L.L. Wiltshire, W.L. Owen, Three Tests of Firehosing Technique and Equipment for the Removal of Fallout from Asphalt Streets and Roofing Materials, USNRDL-TR-1048, U.S. Naval Radiological Defense Laboratory, San Francisco, CA, (1966).

[28] J.D. Sartor, G.B. Boyd, F.J. Agardy, Water pollution aspects of street surface contaminants, Journal Water Pollution Control Federation, 46 (1974) 11.

[29] Appendix K in Appendix VI: Calculation of Reactor Accident Consequences, in: Reactor Safety Study: An Assessment of Accident Risks in U.S. Commercial Nuclear Power Plants, NUREG-75/014, U.S. Nuclear Regulatory Commission, Washington, DC, 1975.

[30] P.H. Jensen, E.L. Petersen, S. Thykier-Nielsen, F.H. Vinther, Calculation of the Individual and Population Doses on Danish Territory Resulting from Hypothetical Core-melt Accidents at the Barseback Reactor, RISO Report No. 356, Riso National Laboratory, (1977).

[31] H.L. Gjorup, N.O. Jensen, P.H. Jensen, L. Kristensen, O.J. Nielsen, E.L. Petersen, T. Petersen, J. Roed, S. Thykier-Nielsen, F.H. Vinther, L. Warming, A. Aarkrog, Radioactive Contamination of Danish Terrirory after Core-melt Accidents at the Barseback Power Plant, Riso Report No. 462, Riso National Laboratory, (1982).

[32] L. Warming, Weathering and Decontamination of Radioactivity Deposited on Asphalt Surfaces, Riso-M-2273, Riso National Laboratory, (1982).

[33] J. Roed, Surface Deposition of Airborne Material Released by a Core-Melt Accident at a Power Reactor, Riso-M-2274, Riso National Laboratory, (1981).

[34] F.J. Sandalls, Removal of radiocaesium from urban surfaces, Radiation Protection Dosimetry, 21 (1987) 4.

[35] Cleanup of Large Areas Contaminated as a Result of a Nuclear Accident, Technical Reports Series No. 300, International Atomic Energy Agency, Vienna, (1989).

[36] Decontamination Guidelines (Tentative Translation), 2nd Ed., http://josen.env.go.jp/en/framework/pdf/decontamination_guidelines_2nd.pdf (accessed August 2015), (2013).

[37] S. Calvert, H. Brattin, S. Bhutra, Improved Street Sweepers for Controlling Urban Inhalable Particulate Matter, EPA-600/7-84-021, U.S. Environmental Protection Agency, Washington, DC, (1984).

[38] L. Warming, Weathering and Decontamination of Radioactivity Deposited on Concrete Surfaces, Riso-M-2473, Riso National Laboratory, (1984).

[39] M.M. Barbier, C.V. Chester, Decontamination of Large Horizontal Concrete Surfaces Outdoors, Conf-800542-2, Oak Ridge National Laboratory, (1990). 
[40] J. Roed, K.G. Andersson, Clean-up of urban areas in the CIS countries contaminated by Chernobyl fallout, Journal of Environmental Radioactivity, 33 (1996) 10.

[41] J. Roed, C. Lange, K.G. Andersson, H. Prip, S. Olsen, V.P. Ramzaev, A.V. Ponamarjov, A.N. Barkovsky, A.S. Mishine, B.F. Vorobiev, A.V. Chesnokov, V.N. Potapov, S.B. Shcherbak, Decontamination in a Russian Settlement, Riso-R-870(EN), Riso National Laboratory, (1996).

[42] J. Sinnaeve, M. Olast, Improvement of Practical Countermeasures: The Urban Environment, Post-Chernobyl Action, EUR 12555 EN, Commission of the European Communities, Brussels, (1991).

[43] I. Vovk, V.V. Blagoyev, A.N. Lyashenko, I.S. Kovalev, Technical approaches to decontamination of terrestrial environments in the CIS (former USSR), The Science of the Total Environment, 137 (1993) 15.

[44] I. Vovk, N.P. Movchan, Y.G. Fedorenko, A.A. Shpigun, B.P. Zlobenko, Research on Cleanup of Buildings and Structures in Urban Areas of Ukraine Affected by the Accident at the Chernobyl NPP, in: United States: American Society of Mechanical Engineers, 1993, pp. 225227.

[45] H. DeWitt, W. Goldammer, H. Brenk, R. Hille, H. Jacobs, K. Frenkler, Decontamination of urban areas after nuclear accident, in: Proceedings of an International Symposium on Recovery Operations in the Event of Nuclear Accident or Radiological Emergency, IAEA-SM-316/44, International Atomic Energy Agency, Vienna, 1989, pp. 355-363.

[46] C.L. Fogh, K.G. Andersson, A.N. Barkovsky, A.S. Mishine, A.V. Ponamarjov, V.P. Ramzaev, J. Roed, Decontamination in a Russian settlement, Health Physics, 76 (1999) 10.

[47] J. Brown, J.R. Cooper, J.A. Jones, L. Flaws, R. McHeary, J. Spooner, Review of Decontamination and Clean-up Techniques for Use in the UK Following Accidental Releases of Radioactivity to the Environment, NRPB-R288, National Radiological Protection Board, Chilton, Oxfordshire, (1996).

[48] K.G. Andersson, Evaluation of Early Phase Nuclear Accident Clean-Up Procedures for Nordic Residential Areas, NKS/EKO-5(96)18, Riso National Laboratory, (1996).

[49] Planning for Environmental Restoration of Radioactively Contaminated Sites in Central and Eastern Europe - Vol. 3 Technologies for, and the Implementation of, Environmental Restoration of Contaminated Sites, IAEA-TECDOC-865, International Atomic Energy Agency, Vienna, (1994).

[50] J. Roed, Deposition and Removal of Radioactive Substances in an Urban Area, NORD 1990:111, Riso National Laboratory, (1990).

[51] J. Roed, K.G. Andersson, H. Prip, Practical Means for Decontamination 9 Years After a Nuclear Accident, Riso-R-828(EN), Riso National Laboratory, (1995).

[52] K.G. Andersson, J. Roed, A Nordic preparedness guide for early clean-up in radioactively contaminated residential areas, Environmental Radioactivity, 46 (1999) 17.

[53] Technologies for Remediation of Radioactively Contaminated Sites, IAEA-TECDOC-1086, International Atomic Energy Agency, Vienna, (1999).

[54] J. Brown, K. Mortimer, K. Andersson, T. Duranova, A. Mrskova, R. Hänninen, T. Ikäheimonen, G. Kirchner, V. Bertsch, F. Gallay, Generic Handbook for Assisting in the Management of Contaminated Inhabited Areas in Europe Following a Radiological Emergency, EURANOS(CAT1)-TN(06)-09-01, Health Protection Agency, Chilton, Oxfordshire, (2007).

[55] Decontamination Effect of Decontamination Work, Ministry of the Environment Japan, (2013). 
[56] V. Fricke, S. Madaris, C. May, ALARA TM 1146 Strippable Coating, WSRC·TR·99-00458, Deactivation and Decommissioning Focus Area, Westinghouse Savannah River Research Center, (1999).

[57] R. Demmer, K. Archibald, J. Pao, M. Argyle, B. Veatch, A. Kimball, Modern Strippable Coating Methods, Waste Management 2005, Tucson, AZ, (2005).

[58] H.N. Gray, B. Jorgensen, D.L. McClaugherty, A. Kippenberger, Smart polymeric coatings for surface decontamination, Industrial \& Engineering Chemistry Research, 40 (2001) 35403546.

[59] K.G. Andersson, J. Roed, Removal of radioactive fallout from surface of soil and grassed surfaces using peelable coatings, Journal of Environmental Radioactivity, 22 (1994) 197-203.

[60] R.R. Parra, V.F. Medina, J.L. Conca, The use of fixatives for response to a radiation dispersal devise attack - A review of the current (2009) state-of-the-art, Journal of Environmental Radioactivity, 100 (2009) 923-934.

[61] B.G. Ahn, H.J. Won, W.Z. Oh, Decontamination of building surface using clay suspension, Journal of Nuclear Science and Technology, 32 (1995) 7.

[62] N. Movchan, Y. Fedorenko, B. Zlobenko, A. Spigoun, Natural Sorbents for Decontamination of Objects of Urban Territories, in: The Radiological Consequences of the Chernobyl Accident, Proceedings of the First International Conference, Minsk, Belarus, 1996.

[63] Water Wash Down of Radiological Dispersal Device (RDD) Material on Urban Surfaces: Effect of Washing Conditions on Cs Removal Efficacy, EPA/600/R-12/068, U.S. Environmental Protection Agency, Washington, DC, (2012).

[64] C. Camarasa-Claret, F. Persin, J. Real, Impact de quelques techniques de lavage sur la decontamination de tuiles et beton contamines par du cesium et du strontium radioactifs, Radioprotection, 35 (2001) 13.

[65] J. Real, F. Persin, C. Camarasa-Claret, Mechanisms of desorption of 134Cs and 85Sr aerosols deposited on urban surfaces, Journal of Environmental Radioactivity, 62 (2002) 1-15.

[66] R. Martin, R. Demmer, Environmentally-friendly removal of surface and sub-surface contaminants, in: Nuclear Decommissioning Report, October, 2011.

[67] M. Kaminski, C. Mertz, M. Finck, M. Kalensky, C. Bishop, J. Jerden, N. Kivenas, Effective and worker-friendly decontamination agents for porous and non-porous building materials, Waste Management Conference 2012, Phoenix, AZ, (2012).

[68] M.D. Kaminski, M.R. Finck, C.J. Mertz, Composition Suitable for Decontaminating a Porous Surface Contaminated with Cesium, U.S. Patent No. 7737320, (2010).

[69] W.R. Selbig, R.T. Bannerman, Evaluation of Street Sweeping as a Stormwater-QualityManagement Tool in Three Residential Basins in Madison, Wisconsin, Scientific Investigations Report 2007-5156, US Geological Survey, 2007.

[70] K.G. Andersson, Countermeasures for reduction of dose in contaminated inhabited areas, Ch. 8, in: Radioactivity in the Environment, Airborne Radioactive Contamination in Inhabited Areas, Elsevier, 2009.

[71] J. Severa, J. Bár, Handbook of radioactive contamination and decontamination, in: Studies in Environmental Science, Elsevier, 1991, pp. 162-335.

[72] P. Lemieux, Technologies to Improve Efficiency of Waste Management and Cleanup After an RDD Incident, EPA/600/R-13/124, U.S. Environmental Protection Agency, Washington, DC, (2013).

[73] J. Drake, R. James, R. Demmer, Side by Side Comparison of Chemical Decontamination Products for Dirty Bomb Cleanup, Waste Management Conference 2011, Phoenix, AZ, (2011). 
[74] Decontamination of Concrete with Aged and Recent Cesium Contamination, EPA 600/R13/001, Technology Evaluation Report, U.S. Environmental Protection Agency, Washington, DC, (2013).

[75] Decontamination of Cesium, Cobalt, Strontium, and Americium from Porous Surfaces, EPA/600/R-13/232, Technology Evaluation Report, U.S. Environmental Protection Agency, Washington, DC, (2013).

[76] Y. Ito, Report of the Results of the Decontamination Model Projects, Japan Atomic Energy Agency, http://www.jaea.go.jp/fukushima/decon04/english/1\%20Overview.pdf, accessed August 2015 (2012).

[77] Japan, Progress on Off-site Cleanup Efforts in Japan, http://www.icrp.org/docs/Tsutomu\%20Sato\%20Progress\%20on\%20Off-

site\%20Cleanup\%20Efforts\%20in\%20Japan.pdf, accessed August 2015, Ministry of the Environment, (2013).

[78] Y. Shiratori, A. Tagawa, Decontamination Technology Demonstration Test Project, http://fukushima.jaea.go.jp/english/decontamination/pdf/3-

1\%20Decontamination_Technology_Demonstration_Test_Project.pdf, accessed August 2015, Japan Atomic Energy Agency, (2014).

[79] K.G. Andersson, J. Roed, C. Fogh, Weathering of radiocaesium contamination on urban streets, walls and roofs, Journal of Environmental Radioactivity, 62 (2002) 49-60.

[80] B. Sawhey, Selective sorption and fixation of cations by clay minerals: a review, Clays Clay Miner, 20 (1972) 93-100.

[81] A. Cremers, A. Elsen, P.D. Preter, A. Maes, Quantitative analysis of radiocaesium retention in soils, Nature, 335 (1988) 247-249.

[82] R. N.J. Comans, M. Haller, P. De Preter, Sorption of cesium on illite: Non-equilibrium behaviour and reversibility, Geochimica et Cosmochimica Acta, 55 (1991) 433-440.

[83] B.Y. Oskolkov, M.D. Bondarkov, L.I. Zinkevich, N.I. Proskura, E.B. Farfán, G.T. Jannik, Radioactive waste management in the Chernobyl exclusion zone: 25 Years since the Chernobyl nuclear power plant accident, Health Physics, 101 (2011) 431-441.

[84] A.S. Paschoa, A.T. Filho, J.J. Rosenthal, Revisiting Goiania: Toward a final repository for radioactive waste, IAEA Bulletin, 1 (1993).

[85] RDD Waste Estimation Support Tool (WEST), Version 1.2, EPA/600/R/12/594, U.S. Environmental Protection Agency, Washington, DC, (2012).

[86] A. Nisbet, J. Brown, T. Cabianca, A. Jones, K. Andersson, R. Hänninen, T. Ikaheimonen, G. Kirchner, V. Bertsch, M. Heite, Generic Handbook for Assisting in the Management of Contaminated Inhabited Areas in Europe Following a Radiological Emergency, Version 2, EURANOS (CAT1)-TN (09)-03, Health Protection Agency, (2010).

[87] P. Hubert, L. Annisomova, G. Antsipov, V.P. Ramzaev, V. Sobotovitch, Strategies of Decontamination, Experimental Collaboration Project 4, European Commission, EUR 16530 EN, ISBN 92-827-5195-3, (1996).

[88] J. Brown, A.L. Jones, Review of Decontamination and Remediation Techniques for Plutonium and Application for CONDO version 1.0, NRPB-R315, National Radiological Protection Board, Chilton, Oxfordshire, 2000.

[89] J. Drake, R. James, R. Demmer, Performance evaluation of decontamination technologies for dirty bomb cleanup, Waste Management Conference 2010, Phoenix, AZ, (2010).

[90] K.G. Andersson, Migration of Radionuclides on Outdoor Surfaces, Ch. 5, in: Radioactivity in the Environment, Airborne Radioactive Contamination in Inhabited Areas, Elsevier, 2009. 
[91] M. Kaminski, C. Mertz, N. Kivenas, Irreversible wash aid additive for mitigation of urban, radioactive contaminations, Waste Management Conference 2014, Phoenix, AZ, (2014).

[92] F.J. Sandalls, Removal of Radiocaesium from Urban Surfaces Contaminated as the Result of a Nuclear Accident, AERE R 12355, United Kingdom Atomic Energy Authority, (1987).

[93] P.V. Samuleev, W.S. Andrews, K.A.M. Creber, P. Azmi, D. Velicogna, W. Kuang, K. Volchek, Decontamination of radionuclides on construction materials, Journal of Radioanalytical and Nuclear Chemistry, 296 (2012) 811-815.

[94] K.M. Thiessen, K.G. Andersson, T.W. Charnock, F. Gallay, Modelling remediation options for urban contamination situations, Journal of Environmental Radioactivity, 100 (2009) 564-573.

[95] National Planning Scenarios: Created for Use in National, Federal, State, and Local Homeland Security Preparedness Activities, Version 21.3, Department of Homeland Security, (2006).

[96] J. Brown, D.J. Hammond, P. Kwakman, Generic Handbook for Assisting in the Management of Contaminated Drinking Water in Europe Following a Radiological Emergency, EURANOS(CAT1)-TN(06)-09-02, Health Protection Agency, Chilton, Oxfordshire, (2009).

[97] M.A. Ebadian, Assessment of Strippable Coatings for Decontamination and Decommissioning, DOE/EW/55094-32, Florida State University, (1998).

[98] J.J. Tawil, F. Bold, Guide to Radiation Fixatives, PNL-4903, Pacific Northwest Laboratory, (1983).

[99] Decontamination of Concrete and Granite Contaminated with Cobalt-60 and Strontium-85, Technology Evaluation Report, EPA/600/R-13/002, U.S. Environmental Protection Agency, Washington, DC, (2012).

[100] Decontamination of Concrete and Granite Contaminated with Americium-243, Technology Evaluation Report, EPA/600/R-13/204, U.S. Environmental Protection Agency, Washington, DC, (2013).

[101] Argonne National Laboratory Argonne SuperGel for Radiological Decontamination, Technology Evaluation Report, EPA/600/R-11/081, U.S. Environmental Protection Agency, Washington, DC, (2011).

[102] J. Drake, Performance evaluation of decontamination technologies for dirty bomb cleanup, Decontamination Research and Development Conference, Research Triangle Park, NC, April 13 (2010). 
Table 2. Summary of research relevant to external building materials and potentially applicable to wide-area mitigation and decontamination [research conducted in the laboratory (Lab) or at the pilot/full scale with real contamination (Field)].

\begin{tabular}{|c|c|c|c|c|c|}
\hline $\begin{array}{l}\text { Type of } \\
\text { Decon- } \\
\text { tamination }\end{array}$ & $\begin{array}{l}\text { Radio- } \\
\text { isotopes }\end{array}$ & Method & Materials & $\begin{array}{l}\text { Lab/Field } \\
\text { Experiment }\end{array}$ & Ref. \\
\hline $\begin{array}{l}\text { Removal of } \\
\text { debris and } \\
\text { dust }\end{array}$ & $\begin{array}{l}\text { All loose } \\
\text { contam- } \\
\text { inations }\end{array}$ & $\begin{array}{l}\text { Remove debris and loose surface material that was exposed to fallout or radioactive } \\
\text { plume. }\end{array}$ & Various surfaces & Field & $\begin{array}{l}{[8,} \\
54, \\
55, \\
96]\end{array}$ \\
\hline $\begin{array}{l}\text { Strippable } \\
\text { coatings }\end{array}$ & $\begin{array}{l}\text { Various } \\
\text { loose } \\
\text { contam- } \\
\text { inations }\end{array}$ & $\begin{array}{l}\text { Several reviews discuss the widespread practice of using strippable coatings to remove } \\
\text { loose, radioactive particles from contaminated nuclear facilities [18,97] and its } \\
\text { potential use after a RDD incident [60]. Andersson [59] tested six strippable coatings } \\
\text { for the removal of contaminated soil. An example of "smart" coatings are given by } \\
\text { Gray [58], where a strong chelator and colorimetric agent were mixed with the } \\
\text { polymer coating to indicate the location of hot spots. Idaho National Laboratory [57] } \\
\text { tested commercial and experimental coatings on contaminated coupons. See [60] for } \\
\text { a thorough review of strippable coatings potentially-applicable to an RDD. See } \\
\text { below in the "Various" methods section for more information on the EPA tests of } \\
\text { strippable coatings for removal of RDD contamination. }\end{array}$ & Various hard materials & Lab and Field & $\begin{array}{l}{[16,} \\
18, \\
57- \\
60, \\
89, \\
97, \\
98]\end{array}$ \\
\hline $\begin{array}{l}\text { Clay film: } \\
\text { Na-bentonite } \\
\text { clay }\end{array}$ & $\begin{array}{c}\text { Soluble } \\
\text { Cs- } \\
\text { 134/137, } \\
\text { Ce-144, } \\
\text { Ru-106 }\end{array}$ & $\begin{array}{l}\text { Used Na-bentonite from Cherkassy deposit of Ukraine as a sprayable slurry } \\
\text { employing a military vehicle with "standard pump equipment." Vladimirovka } \\
\text { contamination was from soluble form of radionuclides. Near the reactor the } \\
\text { contamination was particulate form. Study presented preliminary data. } \mathrm{DF}=2-20 \text { on } \\
\text { whitewashed brick wall, } \mathrm{DF}=2 \text { for smooth concrete, } \mathrm{DF}=3 \text { for roofing slate, } \mathrm{DF}=10 \\
\text { for zinc-coated iron. Heavily weathered surfaces decreased DF. }\end{array}$ & $\begin{array}{l}\text { Smooth concrete, } \\
\text { Roofing slate, Zinc- } \\
\text { coated iron roofing }\end{array}$ & $\begin{array}{l}\text { Field: } \\
\text { Buildings } \\
\text { contaminated } \\
\text { after Chernobyl }\end{array}$ & [44] \\
\hline $\begin{array}{l}\text { Clay film: } \\
\mathrm{NH}_{4}^{+} \text {loaded } \\
\text { bentonite } \\
\text { clay }\end{array}$ & $\begin{array}{l}\text { Soluble } \\
\text { Cs- } \\
134 / 137 \\
\text { Am-241, } \\
\text { Eu- } \\
154 / 155 \\
\text { Ce- } 144\end{array}$ & $\begin{array}{l}\text { Improved on Vovk et al. by using } \mathrm{NH}_{4}^{+} \text {form of } \mathrm{Na} \text {-clay suspension. } \\
\text { Decontamination performed } 3 \text { times. Two Ca-montmorillonite type clays in } \\
\text { suspension with } 0.05 \mathrm{M} \mathrm{Na}_{2} \mathrm{CO}_{3} \text { or } 0.05 \mathrm{MNa}_{2} \mathrm{CO}_{3} / 1 \mathrm{M} \mathrm{NH}_{4} \mathrm{NO}_{3} \text { in "equal volume } \\
\text { of clay" on } 5 \times 5 \times 1 \mathrm{~cm} \text { square samples. Radioactive leachate from Chernobyl soil was } \\
\text { applied to sample face, then aged } 2 \text { days. } 4 \mathrm{~mL} \text { of clay suspension applied and dried } \\
\text { for } 2 \text { days, then removed. Total contamination removal followed indirectly with } \\
\text { increasing porosity: slate }(\mathrm{DF}=3.45-4.55)<\text { silicate brick }(\mathrm{DF}=1.96-2.13)<\text { red brick } \\
\text { (DF=1.28-1.56). } \mathrm{NH}_{4}^{+} \text {suspensions appeared to improve results by }<10 \% \text { total } \\
\text { activity. }\end{array}$ & $\begin{array}{c}\text { Silicate brick, } \\
\text { Red brick, } \\
\text { Slate }\end{array}$ & $\begin{array}{l}\text { Lab: } \\
\text { Coupons }\end{array}$ & [61] \\
\hline
\end{tabular}

Page 25 of $\mathbf{3 2}$ 
Clay film:

Na-bentonite

clay-based

paste
Not No details given. Decontamination with unspecified suspension and "Cleadecon" specified paste with abrasive on rural houses in Vladimirovka and Chernobyl. Decontamination results were: asbocement roof $(\mathrm{DF}=2-5.4)$ and silicate bricks ( $\mathrm{DF}=1.8-4)$ Decontamination depth reported to be $0.1-0.3 \mathrm{~mm}$ for asbocement slate, $0.2-0.3 \mathrm{~mm}$ for tiles, $0.3-0.5 \mathrm{~mm}$ for red brick, $0.5-0.8 \mathrm{~mm}$ for silicate brick, $0.1-0.15 \mathrm{~mm}$ for rusty iron.

Cs-137 Na-montmorillonite clay paste was applied, allowed to dry, and then vacuumed. Decontamination of buildings in Pripyat from 1992 with DF=1.1, but improved clay paste that used palygorskite with bentonite in $1993 \mathrm{had} \mathrm{DF}=1.6$ from sandstone wall.

Fire hosing Particulate The test was conducted 1 and 2 days after atomic detonation. Data on fire hosing and scrubbing (with detergent) a single concrete-slab roof, and on fire hosing a singlecomposition shingle roof. The DF were 2.5-3.3 for: (1) fire hosing a concrete roof (1 pass, 50-psi nozzle pressure); and (2) fire hosing a composition shingle roof. No significant additional amount of fallout was removed from the concrete roof when it was scrubbed after fire hosing.

Fire hosing Particulate tSynthetic fallout experiments. Direct fire hosing with fan-shaped streams and lobbing of standard fire streams were performed on roof areas. Used different fire nozzles at varying range, pressure, and deflection, as well as conventional and modified flusher at different flow rates and pressure. The performance of motorized flushing was superior to that of fire hosing. Portland cement concrete surfaces were consistently easier to clean than asphaltic concrete for either type of decontamination procedure. For roofing, surfaces no rougher than composition shingles, lobbing of fire streams from ground level appears to offer the same degree of removal effectiveness as direct hosing at roof level where roof slopes provide adequate drainage.

Fire hosing Particulate Fire-hosing technique evaluated with inert sand simulant at various mesh sizes (44$700 \mu \mathrm{m})$ spread across surface at $4-100 \mathrm{~g} / \mathrm{ft}^{2}$. Sand tagged with La-140 was dispersed at different mass loadings on asphalt test surface (15' wide x $95^{\prime}$ long). Two firehosing rates with two types of nozzles (standard $5 / 8$ " fire and elliptical flare nozzle). They report: for 44-88 $\mu \mathrm{m}, \mathrm{DF}=6.2$ and 14 for 4 and $24 \mathrm{~g} / \mathrm{ft}^{2}$, respectively, and for 350-700 $\mu \mathrm{m}, \mathrm{DF}=20$ and 33 for 4 and $24 \mathrm{~g} / \mathrm{ft}^{2}$, respectively. [Report states that fire hosing was first method used to decontaminate naval vessels after Operation Crossroads in 1947. Also, references fire-hosing test of fallout simulant in the 1956 Stoneman I Operation (tagged soil dispersed on roofs and paved areas) and test run in the 1958 Stoneman II Operation.]

Asbocement (asbestos- Field: cement) roof,

Tiles, Red brick,

Houses in

Silicate brick,

Rusty iron

Sandstone walls

Field:

Buildings

contaminated

after Chernobyl

contaminated

after Chernobyl
[62]

Field:

Composition shingle Fallout particles

roof

from nuclea

bomb blast .

\section{Portland cement Lab:} concrete, Roadways, roof

Asphaltic concrete

Composition shingles

Asphalt,

Lab:

(references previous $15^{\prime}$ wide and 9

work on roofs and paved long surfaces

areas)

Page $\mathbf{2 6}$ of $\mathbf{3 2}$ 
Fire hosing Particulate Similar to Wiltshire and Owen [26]. Two sizes (88-177 $\mu \mathrm{m}, 300-600 \mu \mathrm{m})$ tagged with La-140 and spread across surface at $5-100 \mathrm{~g} / \mathrm{ft}^{2}$. Used standard fire and flare nozzles to remove particles from road and roof. Fire hosing better with smoother roofing materials and for smoother asphalt (compared to rough asphaltic concrete surfaces tested in 1965 study). Larger sized particles removed better than smaller. Residual mass was typically $<<10 \%$ of original loading.

Fire hosing Soluble * Measurements done at different types of roads and during all seasons, including Rb-86/ winter with snow and ice cover of the roads. Sprayed Cs/Rb solution and let sit

$\mathrm{Ru}-\quad$ outside on concrete surface and asphalt. Let it weather away, decontaminated after $x$ $103 / \mathrm{Ba}-$ days, then weathered away until end of test. Heavy, simulated rain gave $\mathrm{DF}<1.14$ at

140/La- varying contamination age. Fire hosing was generally more effective after short aging $140 \quad(<10 \mathrm{~d})$ than longer aging.

Fire hosing: Soluble *The first experiment consisted of new and old concrete surfaces with almost no plus

Rb-86/ traffic, and new and old asphalt surfaces with moderate traffic load. The second set weathering $\mathrm{Ru}-\quad$ consisted of two areas of new concrete, one of old concrete and one of old asphalt. 103/Ba- Sprayed Cs/Rb solution and let sit outside on concrete surface and asphalt. Then let $140 / \mathrm{La}^{-}$it weather away, decontamination on 7 th day, then weathered away until end of test.

140 Weathering data are of little use because of infrequent rain. Decontamination of 7 day old contamination by fire hosing with a DF of 1.1 and 1.3.

Fire hosing Natural Cs EPA testing of deionized water washing to remove $\mathrm{CsCl}$. CsCl was aerosolized with methanol onto coupons. Using experimental spray chamber, they reported $\mathrm{DF}=3$. for asphalt, $\mathrm{DF}=1.85$ for brick, and $\mathrm{DF}=2.2$ for concrete.

\begin{tabular}{lll}
\hline $\begin{array}{l}\text { High } \\
\text { pressure }\end{array}$ & Cs-137 & $\begin{array}{l}\text { High pressure (65-150 bar) water on asbestos roof, sandstone wall (wet and dry } \\
\text { deposition), clay brick, limed wall, concrete wall and pavement, and asphalt road with }\end{array}$
\end{tabular}

pressure $\mathrm{DF}=1.12-1.67$.
Asphaltum roof

Fiberglass roofing,

Asphalt roof,

280' long x 95'

Composition shingle roofing

\section{Concrete, Field:}

Asphalt roadway

Concrete (new and old), Field: Roadways

Asphalt (new and old)

ith
Asbestos
roof/Sandstone wall
(wet and dry
deposition)/ Clay brick/

Limed wall/ Concrete wall/Concrete

pavement/ Asphalt road

\begin{tabular}{ccl}
\hline Ionic wash: & Rb-86 & *Performed decontamination with potassium-fertilizer but did not provide details \\
Potassium & $\mathrm{Ru}-103$ & except for fertilizer loading (up to $150 \mathrm{~g} / \mathrm{m}^{2}$ ): no effect was observed but data not \\
& Ba140/La- given.
\end{tabular}

Concrete
Asphalt

Field:

$12 \times 10 \mathrm{~cm}$

coupons

Field: Buildings [40]

contaminated after Chernobyl

140

Page 27 of 32 
Ionic wash: Soluble Ammonium Cs-137

Ionic wash: Sodium,

Hydronium,

Ammonium

Ionic wash: Ammonium

\footnotetext{
Report by large, international research team. Decontamination of roof tiles using
} high-pressure washing, $\mathrm{NH}_{4} \mathrm{NO}_{3}$, wet sandblasting, plus soak tests with brick and roof tile in $\mathrm{NH}_{4} \mathrm{NO}_{3}$. Red clay roof tiles from near Gavle taken from building and reconstructed in lab. Decontamination using pressurized water wash, then with $0.1 \mathrm{M}$ $\mathrm{NH}_{4} \mathrm{NO}_{3}$ solution at low pressure, then rinsed with low and high pressure wash, then wet sandblasted. Soaked brick and roof tile in $0.1 \mathrm{M} \mathrm{NH}_{4} \mathrm{NO}_{3}$ for $65 \mathrm{~h}$, repeated, then rinsed in $\mathrm{CsCl}$ solution. Decontamination from roof tiles was first by high pressure water $(\mathrm{DF}=2.2)$, then $\mathrm{NH}_{4} \mathrm{NO}_{3}(\mathrm{DF}=1)$ and finally by wet sandblasting $(\mathrm{DF}=1.11)$. Soak tests gave $\mathrm{DF}=1.4$ from tile and $\mathrm{DF}=1.8$ from brick. Tested brick walls in Gavle by applying $0.1 \mathrm{M} \mathrm{NH}_{4} \mathrm{NO}_{3}$ at low pressure, rinsed, then high pressure water rinse. Added Altradan Foam $(\mathrm{DF}=1.05)$ as final step. $\mathrm{DF}=1.2$ and $\mathrm{DF}=1.15$ with $\mathrm{NH}_{4} \mathrm{NO}_{3}$ wash and $\mathrm{DF}=1$ with foam.

Ionic wash: $\quad$ Cs- $\quad 0.1 \mathrm{M} \mathrm{NH}_{4}{ }^{+}$on sandstone walls in Pripyat $(\mathrm{DF}=3.0)$ and in Vladimirovka $(\mathrm{DF}=1.27)$.

Ammonium 137/134 Pripyat contamination was mostly particles or fuel, while that in Vladimir was by condensed Cs.

Fletton bricks, Ibstock Lab

facing brick, Engineering

brick class $A$ and $B$,

Granite aggregate paving slab, Clay roofing tile,

Redland concrete roof tile, Welsh slate, Asphalt

Concrete paving slabs, $\mathrm{Lab}$

Asphalt layer,

Clay roof tiles

Red clay roof tile, Brick

Field:

Buildings

contaminated

after Chernobyl

Sandstone walls

Field: Buildings contaminated 
Ionic wash: Cs-137, Sr- Tested rain and washings with aggressive solutions on 90-year old clay tiles and 30Ammonium year old concrete pavers contaminated with $\mathrm{Sr}$ and $\mathrm{Cs}$ aerosols simulating a reactor meltdown accident. Performed runoff experiments with rain and salt solutions [0.1 $\mathrm{M}$ and $1 \mathrm{M} \mathrm{NH}_{4} \mathrm{Cl}$ or $0.1 \mathrm{M}\left(\mathrm{NH}_{4}\right)_{2} \mathrm{C}_{2} \mathrm{O}_{4}$. The rainwater proved not to be very effective ( $\mathrm{DF}<<1.11$, except for $\mathrm{DF}=1.43$ for $\mathrm{Sr}$ on concrete) in eliminating the radionuclides. Better efficiency was obtained after $2.5 \mathrm{~h}$ of washing with the $\mathrm{NH}_{4} \mathrm{Cl}$ solution applied directly after the contamination $(\mathrm{DF}=1.11$ from clay tile and $\mathrm{DF}=2.5$ from concrete).

Ionic wash: Cs-134, Sr- Studied the physical and chemical mechanisms of Cs and Sr sorption in the form of Ammonium aerosols indicating a reactor accident source term. Their desorption by rainwater was low (5-6\% for Cs and 29 and 12\% for Sr on tile and concrete, respectively). The desorption of cesium improved strongly with addition of ammonium $(70 \%$ on tile and $90 \%$ on concrete after $24 \mathrm{~h}$ of contact). Sr was less well desorbed $(50 \%$ and $40 \%$, for tile and concrete, respectively).

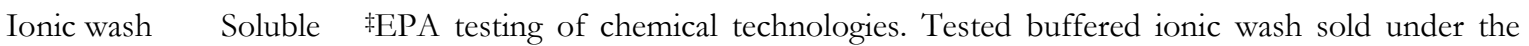
Cs-137, trade name RadRelease ${ }^{\circledR}$ by Environmental Alternatives, Inc.. DF=3.9 and 7.0 for Cs

Co-60, Sr- from concrete (using two formulations of RadRelease ${ }$, respectively), $D F=1.7$ from

90, Am- limestone, $\mathrm{DF}=3.6$ from granite, and $\mathrm{DF}=11$ from marble. For Co, $\mathrm{DF}=5.2$ from 241 concrete and $\mathrm{DF}=3.0$ from granite. For $\mathrm{Sr}, \mathrm{DF}=3.5$ for concrete and $\mathrm{DF}=1.8$ for granite. For $\mathrm{Am}, \mathrm{DF}=9.5$ from concrete and $\mathrm{DF}=2.1$ for granite.

Ionic Wash: Soluble 把A testing of chemical technologies. Tested ionically charged, superabsorbing Ammonium Cs-137, hydrogel ("Argonne SuperGel") that contains salt counter-ions. It is sprayed onto a Co-60, Sr- surface and removed by vacuum. $\mathrm{DF}=3.8$ for Cs from concrete, $\mathrm{DF}=1.2$ for 90, Am- limestone, $\mathrm{DF}=2.0$ for granite, and $\mathrm{DF}=3.5$ for marble. For $\mathrm{Co}, \mathrm{DF}=2.7$ for concrete 241 and $\mathrm{DF}=2.1$ for granite. For $\mathrm{Sr}, \mathrm{DF}=1.7$ for concrete and $\mathrm{DF}=1.5$ for granite. For Am, $\mathrm{DF}=3.3$ for concrete and $\mathrm{DF}=1.5$ for granite.

Ionic Wash: Soluble General method is described for setting up system of berms to contain Ammonium Cs-137

Potassium external structures, using common clay as in situ binder, and collecting and filtering
Clay roof tile,

Concrete pavement

$1 \mathrm{~m} \times 0.5 \mathrm{~m}$

arrays/slabs

Clay tiles

Concrete slabs

Lab:

Coupons

Concrete, Granite,

Marble, Limestone

Lab:

Coupons

$[75$

99

Concrete, Granite,

Marble, Limestone

Lab:

Coupons

Concrete, Asphalt

Lab:

$[75$,

Coupons

the wash water for reuse or disposal. $¥$ Surface washed with $\mathrm{NH}_{4}{ }^{+}$or $\mathrm{K}^{+}$brine and collected. Reported DF=1.3 and 1.6 with large standard deviations on concrete and asphalt, respectively. Vermiculite clay was added to recapture Cs to permit reuse of decontamination wash. $83-92 \%$ of Cs removed by 3 treatments with clay (100 g/L).

Sandblasting Cs- $\quad$ Sandblasting of clay brick and brick wall in Vladimirovka and Pripyat with DF=5.9 $137 / 134(83 \%)$ and $\mathrm{DF}=20$, respectively.

Clay brick, Brick wall

Field: Building

\section{Page 29 of 32}


Particulate tSynthetic fallout was dispersed over pavements and roofs. The performance of motorized flushing was superior to that of fire hosing. An improvised street flusher attachment was found to be satisfactory, and its performance was competitive with the conventional flusher tested. Portland cement concrete surfaces were consistently easier to clean than asphaltic concrete.

Street Particulate Used off-the-shelf street flushers and sweepers. Using a fixed set of flusher sweeping adjustments and constant-size test area, reported on 4 particle size ranges, 3 mass loadings, and 2 types of surfaces. Sand with radiotracer at mass levels of 215-6500 $\mathrm{g} / \mathrm{ft}^{2}$ and various particle mesh $(44-700 \mu \mathrm{m})$. The least effective removal by flushing was obtained at high initial mass loadings $\left(1080-6500 \mathrm{~g} / \mathrm{ft}^{2}\right)$ on asphalt surface using small particles (44-88 $\mu \mathrm{m}$ and $88-177 \mu \mathrm{m})$. The best removal effectiveness by flushing was obtained using low initial mass loading $\left(280 \mathrm{~g} / \mathrm{ft}^{2}\right)$ on concrete surface with 350 $700 \mu \mathrm{m}$ particle sizes.

Street

sweeping

none

Focused on chemical and biological pollution from surface runoff. Reported street sweeper efficiency as a function of particle size and effort.

Street sweeping

Street sweeping none Using contemporary COTS and modified street sweepers, reported resuspension of dust and residual material on street.

Cs-137 Decontamination of roads by hand brooming, street vacuuming, and street wet vacuuming. Concrete and asphalt roads made for this study. After covering road with dust, dissolved Cs was atomized onto surface, then swept by hand broom, vacuum street sweeper, and wet vacuum street sweeper. Varied dust loading. Also tested "wet" deposition of Cs by showering surface with Cs spike solution, rinsing, and drying, then decontamination using dry vacuum street sweeper. At low dust loading $\left(50 \mathrm{~g} / \mathrm{m}^{2}\right)$, very poor DFs $(<1.20)$. At $200 \mathrm{~g} / \mathrm{m}^{2}, \mathrm{DF}=1.67-2.0$ after sweeping, $\mathrm{DF}=1.25$ after vacuuming, and $\mathrm{DF}=1.11$ after wet vacuum. After wet deposition, $\mathrm{DF}=1.11$ from asphalt but $\mathrm{DF}=2.0$ from concrete.
Portland cement concrete, Asphaltic concrete

Asphalt

Concrete

Field:

Roadways
Roadways, roofs

\section{NA Paper study}

Concrete, Asphalt $\quad$ Lab/Field: Coupon and roadways

\begin{tabular}{|c|c|c|c|c|c|}
\hline $\begin{array}{l}\text { Vacuum } \\
\text { cleaning }\end{array}$ & $\begin{array}{l}\text { Soluble } \\
\text { Rb- } 86 / \mathrm{Ru}- \\
103 / \mathrm{Ba}- \\
140 / \mathrm{La}- \\
140\end{array}$ & $\begin{array}{l}\text { *Vacuum cleaning with household vacuum was ineffective, so not recommended for } \\
\text { decon of wet area. }\end{array}$ & $\begin{array}{c}\text { Concrete, } \\
\text { Asphalt }\end{array}$ & $\begin{array}{l}\text { Field: } \\
\text { Roadway }\end{array}$ & [32] \\
\hline
\end{tabular}

\section{Page $\mathbf{3 0}$ of $\mathbf{3 2}$}




\begin{tabular}{|c|c|c|c|c|c|}
\hline $\begin{array}{l}\text { Various: } \\
\text { Sand, water, } \\
\text { detergent } \\
\text { scrubbing } \\
\text { and hosing, } \\
\text { vacuuming }\end{array}$ & $\begin{array}{l}\text { Particulate } \\
\quad(\mathrm{Pu})\end{array}$ & $\begin{array}{l}\text { Tested } 19 \text { surfaces with different techniques using COTS equipment. The most } \\
\text { effective means of hard-surface decontamination in decreasing order of efficiency } \\
\text { was: sand blasting; water-detergent scrubbing; water-detergent hosing; water hosing; } \\
\text { water scrubbing; steam cleaning; and vacuuming. Efficiencies were all above } 66 \% \\
(\mathrm{DF}>2.9) \text {, with the majority above } 95 \%(\mathrm{DF}>20) \text {. }\end{array}$ & $\begin{array}{l}\text { Concrete, Asphalt, Steel, } \\
\text { Aluminum, Galvanized } \\
\text { roofing, Tarpaper } \\
\text { roofing, Wood (painted } \\
\text { and unpainted), Glass, } \\
\text { Brick, Stucco, Shingles } \\
\text { (wood and asbestos) }\end{array}$ & $\begin{array}{l}\text { Field: } \\
\text { Fallout from } \\
\text { Operation } \\
\text { Plumbbob on } \\
2 \times 2,10 \times 10 \\
\text { and/or } 24 \times 50 \\
\text { pads }\end{array}$ & [23] \\
\hline Various & $\begin{array}{l}\text { Not } \\
\text { specified }\end{array}$ & $\begin{array}{l}\text { No details given. Very brief mention of fire hosing, rinsing, washing, high pressure } \\
\text { washing, covering with foam and rinsing, sand blasting, and studies by Sandalls [34]. } \\
\text { Mentions use of "tenside" with alkali carbonates silicates, phosphates, complexing } \\
\text { agents, or protective colloids to improve effectiveness of tensides. }\end{array}$ & Urban surfaces & Paper study & [71] \\
\hline $\begin{array}{l}\text { Various: } \\
\text { Debris } \\
\text { removal, } \\
\text { Roof } \\
\text { washer, } \\
\text { High } \\
\text { pressure } \\
\text { wash }\end{array}$ & $\begin{array}{l}\text { Cs- } \\
137 / 134\end{array}$ & $\begin{array}{l}\text { Novozybkov region in former health resort of twelve small houses and three larger } \\
\text { buildings. Removed debris from roofs. Then, cleaned asbestos sheets by roof washer, } \\
\text { high-pressure water ( } 150 \text { bar) with turbo nozzle, and collected roof runoff. DF=1.5- } \\
\text { 2.0. Included experimental data in Appendix. }\end{array}$ & Asbestos roof & $\begin{array}{l}\text { Field: } \\
\text { Roofs } \\
\text { contaminated } \\
\text { after Chernobyl }\end{array}$ & [41] \\
\hline $\begin{array}{l}\text { Various: } \\
\text { Chemical and } \\
\text { physical } \\
\text { methods }\end{array}$ & $\begin{array}{l}\text { Soluble } \\
\text { Cs-137 }\end{array}$ & $\begin{array}{l}\text { 郎A testing of chemical technologies, mechanical power technologies, strippable } \\
\text { coatings, Simple Green, and water. Cs-contaminated concrete aged 7-10 days. } \\
\text { Tested chemical technologies (EAI Rad-Release I \& II, Rad Decon Solutions Liquid } \\
\& \text { Foam, INTEK ND-75 \& ND-600, Argonne SuperGel, Allen-Vanguard SDF), } \\
\text { mechanical power technologies (sander, rotating water-jet, abrasive blast, wire brush, } \\
\text { diamond flap wheel), and strippable coatings (CBI DeconGel } 1101 \text { and 1108, Isotron } \\
\text { Orion, Bartlett Stripcoat TLC). }\end{array}$ & Concrete & $\begin{array}{l}\text { Lab: } \\
\text { 6"x6" coupons }\end{array}$ & ]$^{[102}$ \\
\hline $\begin{array}{l}\text { Various: } \\
\text { Chemical }\end{array}$ & $\begin{array}{l}\text { Soluble } \\
\text { Cs-137, Sr- } \\
\text { 90, Am- } \\
241, \text { Co-60 }\end{array}$ & 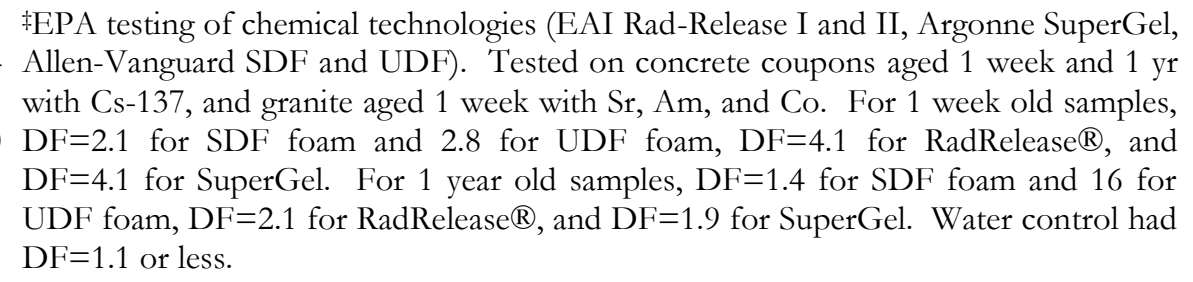 & $\begin{array}{l}\text { Concrete, granite, } \\
\text { marble, limestone }\end{array}$ & $\begin{array}{l}\text { Lab: } \\
\text { 6"x6" coupons }\end{array}$ & [74] \\
\hline $\begin{array}{l}\text { Various: } \\
\text { Physical } \\
\text { methods of } \\
\text { removal and } \\
\text { other } \\
\text { methods in }\end{array}$ & $\begin{array}{c}\text { Cs- } \\
137 / 134\end{array}$ & $\begin{array}{l}\text { Techniques such as removing debris; wiping of gutters, rooftops, and walls; high } \\
\text { pressure washing of drains, gutters, and paved areas; and other novel methods. Very } \\
\text { large data sets with preliminary mean values for urban surfaces reported. Debris } \\
\text { removal and wiping down ( } \mathrm{DF}=\sim 3.3-10 \text { ) proved more effective than high pressure } \\
\text { washing (DF }=\sim 2.5-10 \text { ) for gutter systems. High-pressure wash more effective } \\
(\mathrm{DF}=\sim 1.25-5) \text { for roofs and concrete (with brushing) than wiping alone (DF }=\sim 1.11 \text { - }\end{array}$ & $\begin{array}{l}\text { Various building } \\
\text { materials and roadways }\end{array}$ & $\begin{array}{l}\text { Field: } \\
\text { Municipalities } \\
\text { contaminated } \\
\text { after Fukushima }\end{array}$ & [78] \\
\hline
\end{tabular}

\section{Page 31 of $\mathbf{3 2}$}


develop-

ment

1.42). For asphalt or concrete paving, grinding is generally better than high pressure wash, but both methods are reported quite effective (DF>5). Novel methods include dust-vacuum sander stripping and strippable paints for roofing, "special water" that contains "nanobubbles" and another formulation containing ozone for roadways, and ultra-high pressure water jet ( $>500$ bar) and wet blasting with alumina. Preliminary results show $\mathrm{DF}>5$ using ultra-high pressure water and $\mathrm{DF}=2.5-3.3$ by wet blasting.

\section{NA=Not applicable}

† U.S. military study using synthetic fallout made of dry, tagged soils dispersed over pavements and roofs to simulate the deposition of actual fallout resulting from land surface detonations of nuclear weapons.

* Studied how Danish weather conditions and wash methods influence the decontamination of soluble radionuclides deposited on surfaces.

‡ These studies were completed by the U.S. EPA under the Technology Testing and Evaluation program . 